Portland State University

PDXScholar

5-1-1969

\title{
The Complaint Process in Protective Services for Children
}

\author{
William L. Carey \\ Portland State University \\ Joann Day Delong \\ Barbara Lee Harris \\ Thomas E. Hogan
}

Ann Nelson

See next page for additional authors

Follow this and additional works at: https://pdxscholar.library.pdx.edu/open_access_etds

Part of the Social Work Commons

Let us know how access to this document benefits you.

\section{Recommended Citation}

Carey, William L.; Delong, Joann Day; Harris, Barbara Lee; Hogan, Thomas E.; Nelson, Ann; and Staebler, Jeannette Ruth, "The Complaint Process in Protective Services for Children" (1969). Dissertations and Theses. Paper 918.

https://doi.org/10.15760/etd.918

This Thesis is brought to you for free and open access. It has been accepted for inclusion in Dissertations and Theses by an authorized administrator of PDXScholar. Please contact us if we can make this document more accessible: pdxscholar@pdx.edu. 


\section{Author}

William L. Carey, Joann Day Delong, Barbara Lee Harris, Thomas E. Hogan, Ann Nelson, and Jeannette Ruth Staebler 
AN ABSTRACT OF THE GROUP PROJECT OF William L. Carey

et al. for the Master of Social Work presented May 1, 1969.

Title: The Complaint Process in Protective Services for Children.

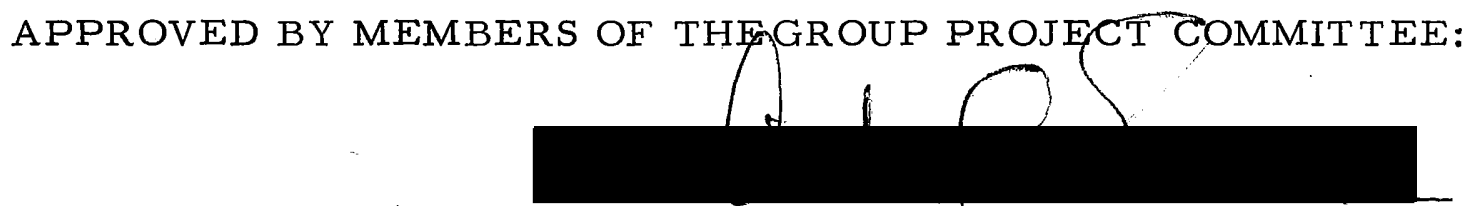

Arthur C. Emlen, Chairman

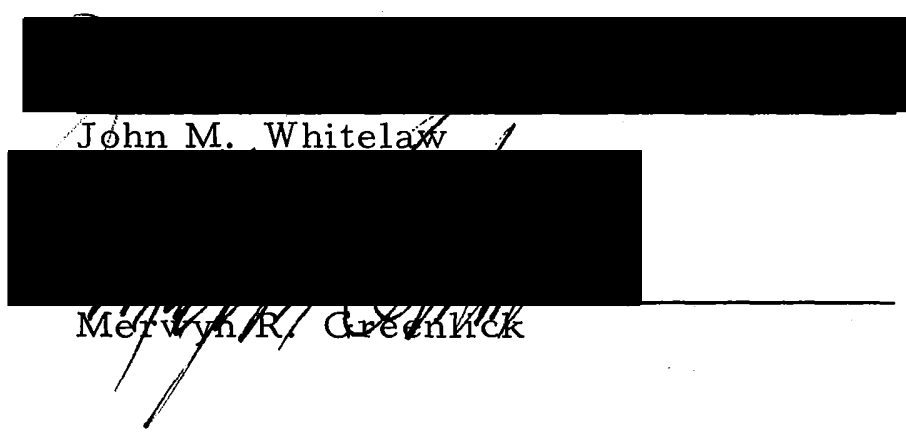

This is a descriptive study of the community process by which a complaint is made to a protective service agency. It is by this process that deviant child care is first identified and the decision to take action is made. The study develops a typology of the complaint process and identifies seven elements as significant in complaints that reach community agencies. The elements were: the complaint situation, the precipitating events that brought the complaint situation to the attention of someone outside the nuclear family, the relationship between the complainant and family, the complainant's 
motivation for responding to the complaint situation, the complainant's justification for making the complaint, the social support for making the complaint sought and received by the complainant, and the complainant's knowledge of an established channel of communication for making the complaint. Essentially the question asked was who complains about what to whom and why.

Data were obtained from questionnaires representing $101 \mathrm{com-}$ plaints about ninety-six families. These questionnaires were completed with information from the Women's Protective Division of the Portland Police Bureau, the Multnomah County Juvenile Court, and the Multnomah County Public Welfare Commission on complaints received primarily during a one month period. Statistical analyses consisted of computer cross tabulations of the study variables.

Two-thirds of the complainants were from the private sector of the community while one-third were agency personnel. Private individuals usually knew of the complaint situation through first hand observation over a period of time. A vast majority of the relatives and one-fourth of the non-relatives who complained had cared for the children in the past. Although only one-fourth of the complainants actually suggested an investigation, three-fourths of the referrals were accepted for service and investigated.

It was found that all of the complaint situations could be clas sified as neglect, abuse, or inadequate supervision. Abuse 
situations were rated highly serious for the child(ren) involved while inadequate supervision situations were rated least serious. In half of the situations reported a breakdown in or a lack of a child care arrangement led to the complaint, usually of inadequate supervision.

The data suggested that a primary element of a successful complaint process is social confirmation and support, especially in situations of neglect which were the most difficult for complainants to evaluate. Motivations for complaints fell into three categories: concern for the child, self concern, and mixed concern. Child concern was most prevalent in situations determined to be highly serious. A universal characteristic was the complainant's need to legitimize the complaint through discrediting the parents involved-"discrediting information" is defined as information which was negative and unrelated to the complaint situation. Strong evidence of discrediting information, however, was associated with neglect rather than with either abuse or inadequate supervision.

The evidence converged on a typology of the complaint process in which each different complaint situation involved a different profile of the complaint process. The essential element of a successful abuse complaint was a highly serious situation; for a successful neglect complaint it was the presentation of discrediting information; and for a complaint of inadequate supervision it was the lack of a child care arrangement. 
Knowledge of the complainant's early diagnosis and motivation for action is essential to the building of a system that will facilitate the reporting of neglect and abuse. 
THE COMPLAINT PROCESS IN PROTECTIVE

SERVICES FOR CHILDREN

by
WILLIAM L. CAREY
THOMAS E, HOGAN
JOANN DAY DELONG
ANN NELSON
BARBARA LEE HARRIS
JEANNETTE RUTH STAEBLER
A group project submitted in partial fulfillment of the requirements for the degree of

MASTER OF SOCIAL WORK

Portland State University
1969 
TO THE OFFICE OF GRADUATE STUDIES:

The members of the Committee approve the group project of William L. Carey, et al. presented May 1, 1969.
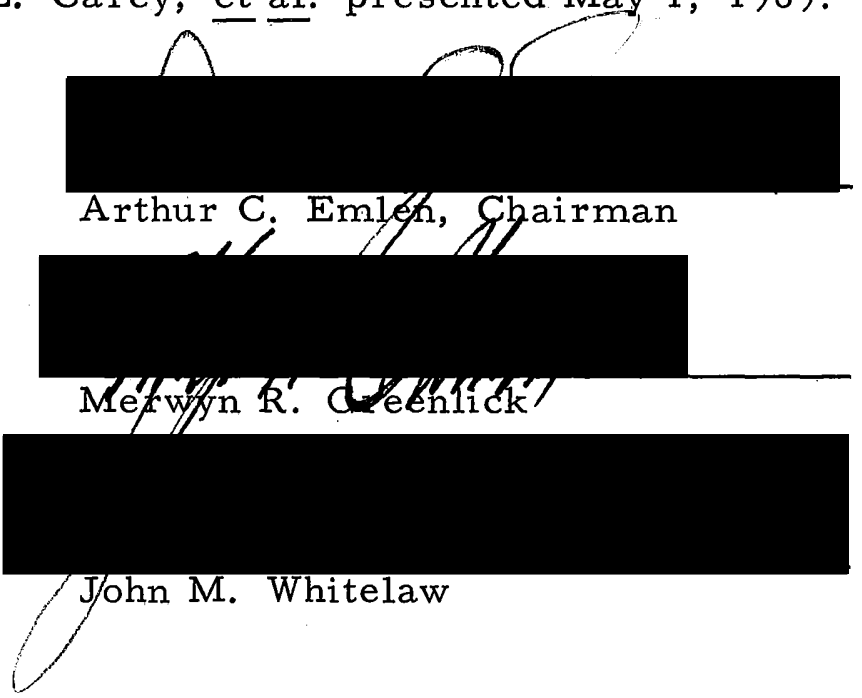

\section{APPROVED:}

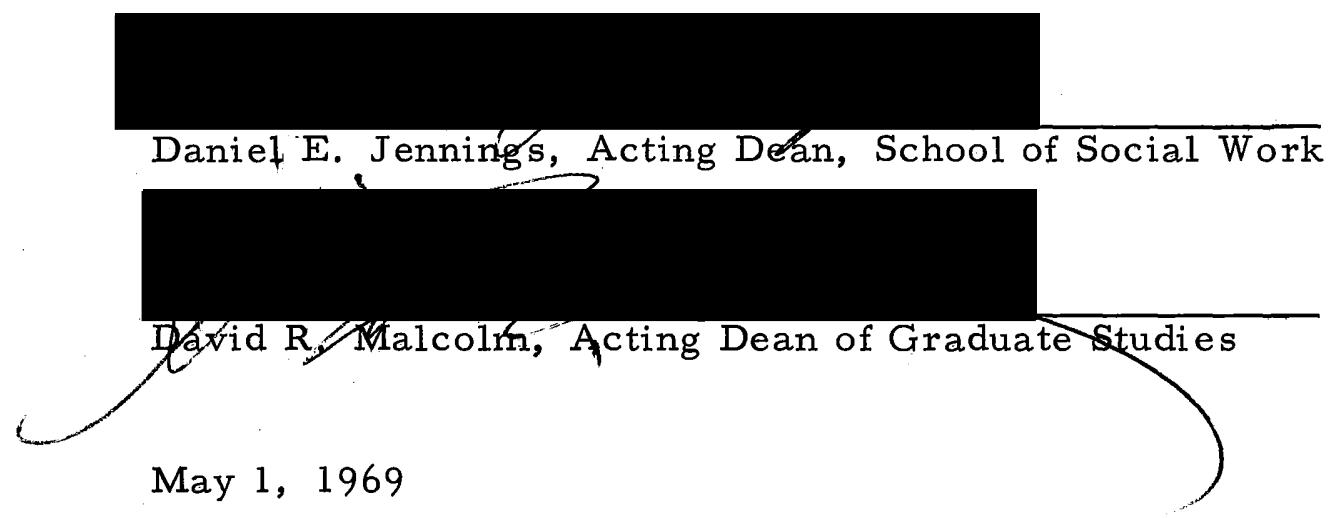




\section{ACKNOW LEDGMENTS}

We wish to express appreciation to many people for their aid in the preparation of this study. We are grateful to the various agency administrators and staff members who gave us their time so

willingly: Mr. Charles Camplan, Mr. Gordon Gilbertson, Miss Helen Lierboe, Mrs. Charles Politz and numerous caseworkers of the Multnomah County Public Welfare Commission; Mr. Bob Dahl and numerous juvenile court counselors of the Multnomah County Juvenile Court; and Captain Elizabeth Mumford and staff of the Women's Protective Division of the Portland Police Bureau.

We also wish to thank Dr. James E. Weiss, Director, Population Research Center, and Mr. Wes Brenner, for their assistance in devising a computer program for our study.

We appreciate the guidance and constructive criticism offered by Professors John M. Whitelaw and Merwyn R. Greenlick.

Above all, we thank our patient and tolerant teacher, Arthur C. Emlen, Associate Professor of Social Work. His unequalled encouragement and guidance helped us more than we can ever fully acknowledge. 
TABLE OF CONTENTS

PAGE

ACKNOWLEDGMENTS . . . . . . . . . . . .

LIST OF TABLES . . . . . . . . . . . . . . . vi vi

LIST OF FIGURES . . . . . . . . . . . . . . . . . ix

\section{CHAPTER}

I THE PROBLEM .............. 1

Rationale ............. . . 1

Review of the Literature ....... 3

Focus and Scope ........... . . . 7

II METHOD OF STUDY . . . . . . . . . 10

Plan for Data Collection ....... 10

Schedule Content .......... 19

Coding the Data........... 22

Reliability of the Coding ....... . 23

Systematizing the Data........ 28

Limitations of the Data........ 31

Validity of the Data......... . 34

III FINDINGS: DESCRIPTION OF COMPLAINT

PROCESSES............ . . 38 
Complaint Situations . . . . . . . . 39

The Complainant ... . . . . . . . . 48

Complainants' Use of Protective

Service Agencies . . . . . . . . 51

Essential Elements of a Successful

Complaint Process . . . . . . . . 54

IV INTERPRETATION OF THE FINDINGS . . . . 70

Typology of the Complaint Process . . . . 70

Further Hypotheses Generated by the

Study. . . . . . . . . . . . 73

Theory of the Complaint Process . . . . 76

V IMPLICATIONS FOR POLICY AND PRACTICE . . 81

A SELECTED BIBLIOGRAPHY • . . . . . . . . . . 89

APPENDICES . . . . . . . . . . . . . . . . . 93

Appendix A: Questionnaire . . . . . . . . . 93

Appendix B: Coding Instructions . . . . . . . . . 97

Appendix C: Individual Code Sheet . . . . . . . . 106

Appendix D: Omission and Consolidation of

Categories for Analysis. . . . . . . .107

Appendix E: Distributions . . . . . . . . . . . 115

Appendix F: Key Punch Coding Form . . . . . . . . 120

Appendix G: Matrix of Correlations Among

Variables Studied. . . . . . . . . . 122 


\section{LIST OF TABLES}

TABLE

PAGE

I Sample of Complaints Regarding Deviant

Child Care...............

II Reliability of Items Requiring Additional

Sampling . . . . . . . . . . . .

III Reliability of Items Requiring Additional

Sampling and Additions to the Schedule...

IV Reliability of Items Requiring Interpretation

of Categories ..............

V Matrix of Correlations Discriminating for Type

of Complaint Situation (TSIT), Seriousness

of Situation (SOS), and Child Care Arrange-

ment (ARNG) by Díscrediting Information

(DISC), Strength of Discrediting Evidence

(EVID), and Motivation for Complaint

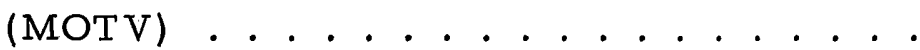

VI Seriousness of Situation by Type of Complaint

Situation for Total Sample. . . . . . . 
VII Child Care Arrangement by Seriousness of

Situation for Total Sample (Percentages). .

VIII Child Care Arrangement by Seriousness of

Situation for Total Sample......... .

IX Complainant's Knowledge of Complaint Situation

by Source of Complaint for Total Sample . .

X Seriousness of Situation by Agency Involved for

Total Sample............... .

XI Discussion of Situation Prior to Complaining by

Agency Involved for Total Sample... . . .

XII Discussion of Situation Prior to Complaining by

Type of Complaint Situation for Total

Sample . . . . . . . . . . . . . . .

XIII Motivation for Making Complaints by Complain-

ant's Relationship to Family for Private

Sector of Community. . . . . . . . .

XIV Motivation for Making Complaints by Type of

Complaint Situation for Total Sample . . . . 
XV Motivation for Making Complaints by Whether

There was a Breakdown in or Lack of a

Child Care Arrangement as a Part of

Complaint Situation for Private Sector

of Community................

XVI Motivation for Making Complaints by Seriousness of Situation for Private Sector of Community .

XVII Tendency to Discredit by Length of Time

Situation had Existed for Total Sample . . . 


\section{LIST OF FIGURES}

FIGURE

PAGE

I Communication Network Illustrating Contacts

Among Community and Agencies . . . . .

58

II Communication Network Illustrating Contacts

Between People at Community Level. . . . .

III Essential Elements of the Complaint Process

Associated with Type of Situation ..... 


\section{CHAPTER I}

\section{THE PROBLEM}

This is a report of a descriptive study of protective service complaints as a social process. The study is an exploration of the community phase of complaints that are successfully lodged with an appropriate agency. It deals only briefly with the response of the agency to the complaint. Essentially the question asked is--who complains about what and to whom and why.

\section{RATIONALE}

Public concern for neglected, abused and exploited children has been evidenced in this country since 1866 when the first case was brought to court in New York, Despite the functioning of protective services since that time, Zalba estimates that there are between 200,000 and 250,000 children in the United States needing protective services each year (1966, p. 8).

Responsibility for initiation of social services for child protection rests largely in the community because few requests for help come from the child's immediate family. The nature of the problem makes it obvious that the parent who has been neglecting or abusing 
his child does not request service of his own volition (De Francis 1961). Thus, the definition of what is deviant child-rearing behavior becomes a joint responsibility of community and protective agency (Boehm 1964). The family's contacts within the community often constitute the source of initial diagnosis of child neglect, abuse, or exploitation and form a "lay referral" network which leads to professional consultation. with an appropriate agency (Landy 1960). This network may include relatives of the family, individuals with whom the family comes in contact, community organizations such as churches and schools, and social agencies who refer the family for protective service.

Awareness of the need for reporting of child abuse has followed identification of the battered child syndrome (Kempe 1962). Increas ingly, states have passed legislation making mandatory the reporting of abuse by professionals who learn of it as a result of their official duties. The fact that such legislation has been necessary to encourage reporting by doctors, teachers, school and public health nurses, social workers, and police personnel (Boardman 1962 and Elmer 1960 ) indicates that there may be even greater impediments to reporting by the layman who is not professionally engaged in responsibility for the welfare of people. The lack of similar specific legal sanction for lay referrals accentuates the tendency of the public not to get involved in the affairs of others (Class 1960). Young (1964) 
states that preventive planning must begin with the identification of children who need protective services. Someone must take responsibility for reporting and there must be a community structure with clear channels of communication that are known to the public.

It is this community process which precedes protective action, and the elements that constitute the process that are explored in this study. Knowledge of this early diagnosis and the motivation for action upon it is essential to the building of a system to facilitate such reports.

\section{REVIEW OF THE LITERATURE}

A survey of literature shows an increasing interest in the problem of child neglect and abuse during recent years. However very little attention is given to the initial complaint action or to the community processes by which deviant child care is initially identified.

A search of the journals in the fields of child welfare, social work, and probation and parole indicates that most of the attention has been given to these areas: (1) descriptions and typologies of neglect and abuse situations, (2) profiles of families that neglect and abuse their children, (3) legal bases for intervention and operation of the legal system in neglect and abuse cases, (4) treatment of identified neglect and abuse and the operation of protective services, (5) coordination and cooperation between community organizations in 
the treatment and identification of neglect and abuse.

The community phase preceding the initiation of protective services has been largely ignored by those who have investigated this problem. Boehm (1964) recognizes that the community shares with the agency the responsibility for decisions about the need for intervention:

Someone in the community must feel strongly enough about the behavior and consider the need for community intervention serious enough to take steps to lodge a complaint with the protective agency. (p. 453)

Young (1964) points out the need for more widespread assumption of responsibility for identification by individuals and agencies who come in contact with neglectful and abusive families.

The impediments to careful appraisal of the child's situation are noted by Boardman (1962). She points out that doctors, nurses, and policewomen identify with the parents unless the situation is grossly obvious or suggests sexual attack. In the extreme situations there is more likely to be an identification with the child and a punitive attitude toward the parent. The existence of a societal taboo that prevents the recognition of the possibility of abuse and leads middle-class professional people to disregard the evidence is discussed by Elmer (1966).

Jeter (1963) surveyed child welfare services and presents distributions of the sources of protective service referrals to private 
and public agencies.

A study of community attitudes toward protective service and the influence these attitudes have upon professional staff was made by Streshinsky, Billingsley andGurgin (1966). The community influence is reflected in the orientation toward use of law enforcement by public welfare personnel.

Gil and Noble (1967) studied public knowledge, attitudes, and opinions about child abuse. Of special interest is data recording how respondents thought they would react upon learning that a child had been abused or on witnessing the abuse. The respondent's knowledge of community resources and their use was assessed.

The literature on social process in the community contributes to the understanding of the complaint process. Landy(I960), Fellin (1968), and Garfinkel (1956) are to be noted for their contributions.

Fellin emphasizes that the norms of the neighborhood are important aspects of social control. The neighborhood serves as a first resource for problems that cannot be resolved within the family.

The "lay referral" system as a first resort of the individual seeking help is discussed by Landy. Similar networks within the community are reported upon in this study. Although Landy was writing about the individual seeking help for himself, similar patterns were found in the present study: when a citizen sought help for an abused or neglected child. 
To respond protectively toward someone else's child, however, inevitably involves some degree of complaint about the behavior of the parents of the child. In the present study the content of the se complaints was analyzed and found to contain not only reference to specific parental behaviors affecting the child--neglect or abuse-but also a variety of information about the parents' drinking, past hospitalization, etc., that presumably was presented to provide some understanding of the deviance of the parental behavior and that tended to discredit the parents as immoral or incompetent.

The complaint process, and especially the prevalence of discrediting information in the complaints, points to the applicability of Garfinkel's (1956) analysis of the conditions of successful degradation ceremonies. The denouncer (complainant) must get witnesses (agency) to appreciate the characteristics of the perpetrator (bad parent) as a type that is a reversal of the sacred (good parent). The denouncer identifies himself with the group values and delivers the denunciation in their name. "In our society the tribal council has fallen into secondary importance; among lay persons the denunciation has given way to the complaint to the authorities" (p. 422). Garfinkel's work was found useful in interpreting the function of some of the behaviors found to be characteristic of the complaint process. 


\section{FOCUS AND SCOPE}

One of the initial aims of the study was to investigate the link between the breakdown of child care arrangements and protective complaints to community agencies. The existence of such a link was suggested by reports from shelter care agencies in Portland. Some of the children brought in to shelter care were referred by babysitters or persons who had had a child care responsibility for the children. These agency reports of complaints revealed from the agency side the existence of a complaint process that a Portland study was investigating at the neighborhood level where child care arrangements are found to break down and elicit the concern of neighbors (Emlen 1968). Initially, the variables to be explored included the proportion of all complaints that are related to a breakdown in or lack of substitute child care arrangements, the geographical distribution of such complaints, the complainant's involvement in the child care situation, and the exploration of the nature of the complaint and referral process. An objective was to make an assessment of the need for child care services in the light of the information that had been gathered.

In the process of formulating the focus and scope of the present study, however, it was decided not to attempt to test hypotheses about the relationships between such variables. It became evident 
that a more basic description of the complaint process was needed first, in order to determine the essential elements of a complaint that initiates some action by a community agency. In response to this need the research team reformulated the objectives of the study to focus upon the development of a typology of the complaint process. This typology incorporates a child care dimension as well as other factors that influence the manner in which complaints are made.

The question asked is, what are the significant elements of the complaint process and do they relate to each other?. The selection of these elements is the hypothesis that is to be explored. Seven elements were identified for study:

(1) The complaint situation, that is, the situation in the family that constitutes some kind of threat to the child.

(2) The precipitating events that brought the complaint situation to the attention of the complainant or persons outside of the nuclear family.

(3) The relationship between complainant and family, that provides the basis for the complainant's observation of, or knowledge of, the complaint situation.

(4) The complainant's motivation for responding to the complaint situation.

(5) The complainant's justification or reasons for making the complaint. 
(6) The social support for making the complaint sought and received by the complainant.

(7) The complainant's knowledge of an established channel of communication for making the complaint.

The complaint situation is that situation that is described by the complainant to the authority he contacts. No distinction has been made between "true" or "false" information. The many legal and social definitions of neglect and abuse have not been used in determining if the complaint is justified. The definition of the complainant that this situation is deviant child care and "needs to be looked into" has been accepted.

The study has been limited to the complaint itself and the immediate reaction of the agency. It does not explore later information obtained by the agencies or what plan was made to deal with the situation.

Subsequent chapters will describe the methods used in the study, the description of the complaint process, a discussion of the findings, and their implications for social policy and social work practice, 


\section{CHAPTER II}

\section{METHOD OF STUDY}

This chapter describes the methods that were developed to obtain and analyze data that would lead to a typology of the complaint process. The specific objectives were to determine the significant elements of the process and to determine how these elements were related. The following sections include a discussion of the plan for data collection, the sample, the content of the schedule--including conceptualization of the phases of the complaint process, methods for coding the data, methods used to determine the reliability of the coding, methods for systematizing the data, the limitations of the data, and the validity of the data.

\section{PLAN FOR DATA COLLECTION}

Complaints regarding deviant child care are lodged with both public and private agencies. Of the many agencies in Multnomah County that were potential sources of data, the Women's Protective Division of the Portland Police Bureau, the Multnomah County Juvenile Court and the Multnomah County Public Welfare Commission were selected to participate in the study. These agencies were 
chosen because they are the primary agencies in Multnomah County prepared to receive and take action in connection with complaints of child neglect, abuse, and/or exploitation, Many of the people in the community are aware of these agencies as appropriate places to lodge a complaint.

The primary function of the Women's Protective Division is protective and preventive work with women and children within the city of Portland who have been reported to the police. Its services include dealing with situations involving delinquent and dependent girls under age eighteen and boys under age twelve. It investigates conditions reported as hazardous to children and attempts, often in cooperation with other law enforcement agencies and social agencies, to correct conditions which are found to be detrimental to children (Tri-County Community Council 1965).

As well as having exclusive jurisdiction over cases of delinquency, the Multnomah County Juvenile Court has, by statute, exclusive jurisdiction over cases of dependency and neglect (Tri-County Community Council 1965). Twelve of the thirty counselors at the Juvenile Court deal with referrals regarding deviant child care. Eight of the twelve counselors receive referrals made to the court by various agencies or individuals in the community including the county and city police, the Women's Protective Division, schools, social agencies, and parents and citizens who feel that the case should 
receive consideration by the court. Four of the twelve counselors handle the referrals made to the court by hospitals and doctors regarding battered or abused children. The Juvenile Court does not classify children thirteen or older as abused nor does the agency classify any cases as delinquency when the children involved are twelve years of age or younger. The court does not accept anonymous complaints but refers them to the welfare department for investigation due to the difficulty involved in taking legal action when the complainant will not identify himself.

Among the functions of the Multnomah County Public Welfare Commission is the administration of all categories of child welfare services in the county in accordance with state laws and the State Public Welfare Commission regulations (Tri-County Community Council 1965). Through the Children's Department county-wide services are offered for children including protective services to neglected and abused children. The Children's Department intake unit is the receiving arm of the Children's Department for new complaints from private individuals and agencies regarding abused, neglected or dependent children. Shelter Care is a specialized unit within the Children's Department. Its primary purpose is to provide emergency placement in homes for children who have been abandoned or who can no longer remain in their own home. The Shelter Care unit operates on a twenty-four hour basis. It typically supervises 
children referred by police departments or the Multnomah County Sheriff's Department; it does not receive complaints from private individuals. In order to carry out its primary function, this unit maintains shelter care homes and, if necessary, places the children received by them in foster care. The Family Service units offer help through basic public assistance programs, protective services for children and adults in their own homes, and related social casework services (Tri-County Community Council 1965).

When the above agencies were contacted during the spring of 1968, they indicated willingness to participate in the study. Prior to the time the study began members of the research team met with one or more representatives from each agency to explain the rationale for the research project and to determine the most effective means for collecting the desired data from the agency.

A questionnaire was developed for eliciting and organizing the data about the complaint process. The research team planned to pretest the questionnaire, evaluate it, revise it and then prepare a final draft which could be completed by agency personnel at the time they received complaints regarding deviant child care. The pretest was to include all the complaints received by the Children's Department intake caseworkers and the Shelter Care unit caseworkers during the week of July 29,1968 . The revised questionnaire was to be com:pleted on complaints made to the Women's Protective Division, the 
Multnomah County Juvenile Court and selected units of the Multnomah County Public Welfare Commission during the period from August 15, 1968 through September 15, 1968. The revisions and deviations from this plan will be described below.

The Captain of the Women's Protective Division indicated that the routine reports made by her staff contained the information being sought with the exception of the community involvement phase of the complaint process, i.e., the contacts the complainant made with others in connection with the complaint situation prior to contacting the Women's Protective Division. She believed that this could be obtained at the time referrals were made to the agency and incorporated into the routine reports. The data were obtained from a copy of routine reports written during the period from August 15, 1968 through September 15, 1968 regarding deviant child care. The information was transferred from the police reports to the questionnaire by two members of the research team.

In order to prevent duplication of time and effort, complaints made to the Juvenile Court during the period from August 15, 1968 to September 15, 1968 were screened to eliminate complaints referred by the Women's Protective Division or referred to the Shelter Care unit of the Multnomah County Public Welfare Commission. During the month the data were being collected the Juvenile Court ledger was examined weekly for those cases recorded as neglect or 
dependency. The counselor for each child identified as dependent or neglected was contacted to learn whether the case was appropriate for the research project. If it was appropriate, the court counselor completed the questionnaire or a member of the research team completed it during an interview with the counselor. It was found, in many instances, that the children identified as neglected or dependent children had been referred to the court because of delinquent behavior but were categorized as neglected or dependent because they were under twelve years of age,

The intake caseworkers in the Children's Department and the Shelter Care caseworkers receiverall the complaints made to the Children's Department regarding deviant child care. Family Service caseworkers also receive complaints regarding families they are working with. The intake workers for the Children's Department and the caseworkers in the Shelter Care unit agreed to complete questionnaires on any complaints received during the week of the pretest and during the period from August 15, 1968 through September 15, 1968. Caseworkers representing two Family Service units also agreed to participate in the study from August 15, 1968 through September 15, 1968.

During the week of July 29, 1968 when the questionnaire was pretested, seven questionnaires were completed by Children's Department intake caseworkers and four questionnaires were completed 
by Shelter Care caseworkers. Although questionnaires were only to be completed on complaints received during that week, the dates the complaints were made to the agency ranged from March 18, 1968 through August 6, 1968. The date of one complaint was unknown. Because only three minor changes were made on the pretest questionnaire for the purposes of clarification and because these changes did not affect the content of the information elicited, the data obtained on the eleven pretest questionnaires were included in the final analysis.

Data collection for the study concentrated on the one month period from August 15, 1968 through September 15, 1968. Of the 103 questionnaires completed during this period of time, thirty were completed regarding complaints that had been made to an agency outside this one month period. With the inclusion of the eleven pretest questionnaires, a total of 114 questionnaires were completed for the study. The sample of complaints is shown in Table I.

Because the study focused on the complaint process, the complaint was the unit of analysis for the study. In several instances one agency received a complaint and referred it on to one or both of the other agencies involved in the study. For example, the Women's Protective Division received a complaint from the Bureau of Sanitation regarding inadequately supervised children. The Women's Protective Division referred this complaint to the Juvenile Court who 
TABLE I

SAMPLE OF COMPLAINTS REGARDING DEVIANT CHILD CARE

\begin{tabular}{lcc}
\hline \hline & Number of & Dates of \\
& Question- & Complaints \\
Sample & naires & Included in \\
Source & Collected & Sample \\
\hline
\end{tabular}

Multnomah County Welfare Department:

\begin{tabular}{lcc} 
Children's Department & 20 & $3 / 18 / 68-9 / 12 / 68$ \\
Shelter Care Unit & 19 & $7 / 12 / 68-9 / 10 / 68$ \\
Family Service Unit & 3 & $7 / / 68-8 / 23 / 68$ \\
ltnomah County Juvenile Court & 11 & $8 / 8 / 68-8 / 29 / 68$ \\
men's Protective Division & 61 & $7 / 18 / 68-9 / 16 / 68$ \\
\hline
\end{tabular}

referred it on to the Children's Department. Although questionnaires had been completed by the Women's Protective Division, the Juvenile Court, and the Children's Department, this was treated as one complaint. In one situation a complainant wrote to the Welfare Commis sion and to the Women's Protective Division simultaneously regarding the same situation; this was treated as one complaint. Complaints received by an agency from one person regarding two different families also were treated as one complaint. In one instance two separate complaints about the same family were combined in error. When different data appeared on different questionnaires 
involving the same complaint, these were combined. For example, one complaint made to the Juvenile Court classified the complaint situation as one involving inadequate food and inadequate medical care while the Children's Department classified the complaint situation as one involving abuse and inadequate physical care. When the two questionnaires were combined, all four characteristics of the complaint situation were used.

Two questionnaires were excluded from the sample. One was excluded because the situation was a request for service by a mother rather than a complaint regarding deviant child care. The other was excluded because the information used to complete it was gleaned from a supplemental report, rather than an original report of deviant child care, which had been received from the Women's Protective Division.

In order to determine the number of families involved, the family names were listed in alphabetical order and the names, ages, and numbers of children in the family were listed and compared. In the six families where no family name was given, it was determined that these were different families through comparing the names, ages, and numbers of children involved.

Out of a total of 114 questionnaires involving complaints made to the three agencies where concern was expressed about the care of a child, the combining and excluding of questionnaires reduced the 
sample size to 101 . These 101 complaints involved a total of ninetysix families.

\section{SCHEDULE CONTENT}

In order to develop a typology of the complaint process it was necessary to elicit data which would make it possible to determine the essential elements of a successful complaint, i. e., the lodging of a complaint with a community agency that is prepared to initiate some action.

Because basic knowledge was sought regarding the complaint process up to the time the complaint was lodged with an agency, an attempt was made to learn the histo ry of each complaint, the motivation for the complaint, the kind of social relationship between the complainant and the family, and whether or not a breakdown in or lack of child care was associated with the type of complaint situation. Other dimensions of the complaint process that were explored were the complainant's knowledge of the agency's functions based on action the complainant recommended, and the action the agencies initially. took in response to a given complaint.

A questionnaire was designed for the use of the community agencies at the point of intake for any complaint in which concern was expressed about the care of a child. While recognizing that there may be a link between delinquency and neglect, the 
questionnaires were not to be completed when delinquency was the primary reason for the referral. However, if the complaint was made primarily because of deviant child care resulting in neglect, abuse, abandonment, or inadequate parenting rather than because of the delinquent behavior of a child, questionnaires were completed.

To obtain the data needed to determine the significant elements of the complaint process the questionnaire was divided into four major sections: the content of the complaint, the observation of the complaint situation, community involvement in the complaint process, and disposition and additional information. Under the section on the content of the complaint the team hoped to solicit specific information about who complained about what to which agency, why the complainant decided to make the complaint at that specific time, and what action, if any, the complainant thought should be taken. Of the seven' elements identified for study in the first chapter, four were obtained from this first section: the description of the complaint situation, the precipitant of the complaint, the complainant's motivation for responding to the situation, and the reason or justification for making the complaint.

The complainant's knowledge of the situation was a fifth element selected for study. It was obtained from the second section of the questionnaire, the observation of the complaint situation. Here the research group attempted to elicit specific information about how 
the complainant knew about the situation, what the relationship was between the complainant and the family, how long the situation had existed, and whether the complainant was caring for, or had cared for, the child(ren) involved. This section also elicited further information regarding the child .care dimension including whether a breakdown in or lack of a child care arrangement was involved in the complaint situation and, if so, who was supposed to be providing the child care and how the arrangement broke down.

The final two elements selected for study were the support the complainant received prior to making the complaint and the complainant's knowledge of an established channel of communication for making the complaint. These elements were elicited for study from the third section of the questionnaire, the community-involvement phase of the complaint process. The complainant's community contacts leading up to contact with the agency, the purpose of these contacts, and the sequence of contacts, were requested. From this information the communication networks involved in each of the complaint processes were diagramed to illustrate how the communicative acts moved from the private sector of the community to community agencies (the history of the complaint).

The final section of the questionnaire was designed to determine the agencies' initial response to the complaint. 


\section{CODING THE DATA}

The data was coded according to the master classification sheet and the coding instructions shown in Appendices B and C. An individual code sheet was used to record the information for each case. The coders marked the appropriate blank for a particular item on the individual code sheet. For example, in item I-A (source of complaint) thecoders indicated that the complaint came either from agency personnel (box a) or from a private individual (box b) but not from both. Seventeen items were coded with mutually exclusive categories while the coders checked all categories that applied for seven items.

The majority of items in the schedule were nominal items, that is, a series of classes of categories with no order relationships manifested by the numbers assigned to the categories (Senders 1958). In item I-A, for example, the coders indicated the source of the complaint as "agency personnel" or "private individual." No order or relationship existed between the two categories. A few items, however, did contain order relationships and were thus ordinal scales (Phillips 1966). In item I-C (seriousness of the situation) the coders assigned a ranked value of one to four to describe a condition of ascending seriousness. The number 4 indicated a condition more serious than the number 3 and so on. Likert-type scales, 
interval $l_{11}$ scales and ratio: scales were not utilized. The items were non-parametric or distribution-free in the sense that no assumptions were made about the precise form of the sample as to imply a completely specified population distribution as in a normal curve or parameter, (Anderson and Zelditch 1968, and Siegèl 1956).

\section{RELIABILITY OF THE CODING}

"A measuring instrument," states Phillips, "is reliable if it yields the same result in repeated application to the same phenomena" (Phillips 1966, p. 163). The measuring instrument was the judgment of the coders; therefore their judgment had to be tested in repeated applications to all the items on the schedule. Each item was coded by two coders who completed a single item for all the cases rather than coding case by case. Thus, all the cases were coded for item I-A before proceeding to item I-B and so on.

All the members of the group participated in the coding. Two coders initially agreed on the item to be coded. They then selected ten cases at random from the sample and each coded independently according to the instruction sheet. When both had completed ten they compared their results to determine their reliability. If they agreed in all the responses they often proceeded independently to code that item for the remainder of the cases. If a lower reliability 
was obtained they attempted to reconcile their differences. After doing this they selected another ten cases and repeated the same process. A third, fourth, or fifth sample might be selected before the coders achieved sufficient reliability to proceed independently.

Four items (I-A, I-H, I-I, and II-A-2) yielded 100 per cent reliability on the first sample with no code changes. No interpretation was needed, for example, to discriminate an agency from a private individual as the source of a complaint.(item I-A).

Six items (II-C-1, II-C-2, II-D-1, II-D-2, II-F-1, and II-F-2) yielded 100 per cent reliability on the first sample but required minor changes in the schedule (see Appendix D for these changes).

Five items. (I-G-1, II-A-1, II-B, II-E-1, and IV) yielded high reliability but required more sampling by the coders. See Table II.

TABLE II

RELIABILITY OF ITEMS REQUIRING ADDITIONAL SAMPLING

\begin{tabular}{lcc}
\hline Item & $\begin{array}{c}\text { Number of } \\
\text { Samples }\end{array}$ & $\begin{array}{c}\text { Reliability } \\
\text { (in \%) }\end{array}$ \\
\hline I-G-1 & 5 & 94 \\
II-A-1 & 4 & 90 \\
II-B & 4 & 85 \\
II-E-1 & 2 & 100 \\
IV & 2 & 95 \\
\hline
\end{tabular}


Four items (II-A-3, II-E-2, I-F, and III) yielded high reliability but required additions to the schedule in addition to more samples. In item II-A-3 (relationship between complainant and family), for example, the coders added category "landlord or apartment manager" to the "non-relative" sub-item and category "law enforcement agency" to the "agency personnel" sub-item. See Table III.

TABLE III

RELIABILITY OF ITEMS REQUIRING ADDITIONAL SAMPLING AND ADDITIONS TO THE SCHEDULE

\begin{tabular}{lcc}
\hline \hline Item & $\begin{array}{c}\text { Number of } \\
\text { Samples }\end{array}$ & $\begin{array}{c}\text { Reliability } \\
(\text { in \%) }\end{array}$ \\
\hline I-F & 6 & 80 \\
II-A -3 & 1 & 90 \\
II -E -2 & 2 & 95 \\
III & 3 & 86 \\
\hline
\end{tabular}

Three items (I-D, I-E, and I-G-2) yielded high reliability but required both more samples and interpretation of the items. The coders determined, for example, in item I-D (discrediting information) that a complainant did not have to actually say the parents were "mentally ill" but could describe symptoms which could be commonly identified by the coders as mental illness. See Table IV. 
TABLE IV

RELIABILITY OF ITEMS REQUIRING INTERPRETATION OF CATEGORIES

\begin{tabular}{lcc}
\hline Item & $\begin{array}{c}\text { Number of } \\
\text { Samples }\end{array}$ & $\begin{array}{c}\text { Reliability } \\
\text { (in \%) }\end{array}$ \\
\hline I-D & 3 & 90 \\
I-E & 3 & 90 \\
I-G-2 & 5 & 90 \\
\hline \hline
\end{tabular}

Two items (I-B and I-C) presented more difficulties to the coders than the above and could not be resolved so easily. They both involved larger samples and more involved problem solving. Item I-B (situation complained about) was particularly difficult: (1) it contained numerous categories, many of which overlapped, (2) the coders were to check all categories that applied, and (3) all the various types of situations had not been anticipated in the coding instructions. On the first sample the coders agreed on twenty-four of thirty possible responses for 80 per cent reliability; divergence of results and differences in interpretation necessitated the use of additional samples. The coders, for example, used "abandonment" only when an actual abandonment occurred, not for being left without a sitter. They included the latter under "neglect-inadequate supervision. "The coders agreed on twenty-four of twenty-seven 
responses on the second sample for 89 per cent reliability and on thirty-six of thirty-six responses on the third. This sample seemed to indicate that differences had been resolved and definitions were sufficiently clear to allow independent coding. The overall reliability figure was eighty-four of ninety-three responses or 90 per cent.

Item I-C (seriousness of situation) presented different difficulties. This item was an ordinal scale and required the coders to judge the degree of seriousness on an ascending scale. Coding of this item was unique in that the reliability figure did not increase significantly with the use of more samples to enable the coders to proceed independently. Every case in the sample was coded by both coders and the reliability figures were: $70,70,70,70,70,70,80$, $60,90,90,80$. All differences were resolved.

The overall results indicate that the coding was highly reliable. The mechanics were designed to eliminate individual variation. Two coders worked independently on every item and results were checked and additional samples selected when necessary. All differences were resolved. Reliability figures were invariably high and, with the exception of item I-C, increased with the use of additional samples. 


\section{SYSTEMATIZING THE DATA}

Once the data had been coded frequency distributions were tabulated ( $\mathrm{N}$ equals $10 \mathrm{l}$ ). The frequencies revealed the distributions for the various items and hence were significant information in themselves; further results were obtained, however, by cross tabulating the items to discover relationships. The research group arranged the data to be analyzed using a cross-tabulation program developed for the IBM 1130 by $\mathrm{J}$. Weiss and W. Brenner. The program could handle a maximum of ten tables and thirty variables per run, cross tabulating any two variables while controlling for a third if desired. It also provided a chi square, gamma, and lambda for each table. For a two-by-two table, the gamma is equivalent to Yule's $Q$ (Goodman and Kruskal 1954). Key punching was done by two of the group members and independently verified.

The group used several different procedures to revise the data: (1) elimination of categories with no responses, (2) elimination of sub-items and sub-categories, (3) consolidation of categories, and (4) resolution of those items in which the coders had checked more than one category.

First, the twenty-four categories with no responses were eliminated from the schedule. Then all the items were numbered in ascending numerical order. Sub-items in I-B (situation complained 
about) and II-A-3 (relationship between complainant and family) became separate items to bring the total to thirty.

Categories were consolidated for two reasons, to reach the maximum of ten for some items and in others to use the data in the most meaningful way. The former was true for three items (I-B-l, I-D, and II-A-3). The category "failure to send to school" (one response) in item I-B-1 (situation complained about--neglect), for example, was omitted and the response included in "other." The second rationale was used in seven categories (I-E, I-F, I-G-1, II $-A-1$, II $-A-3$, II $-F-1$, and II-F-2). Subcategories of item II-A-3 (relationship between complainant and family), for example, were eliminated and the item classified as: (1) relative, (2) non-relative, (3) agency personnel, and (4) unknown. Other consolidations can be found in Appendix D.

Finally, the group resolved those five items (I-H, I-D, I-G-2, IV, and I-B) in which the coders had checked all categories that applied. Item I-H (age) could not be resolved in any meaningful fashion, as there was no rationale short of arbitrariness for choosing one age category over another. This item consequently was not cross tabulated.

The group resolved three items (I-D, I-G-2, and IV) by retaining only one response for each case. This was done independently by two coders and all differences resolved. In item I-D (discrediting 
information) thirty-one cases were involved. The coders first combined "excessive drinking" with "immoral behavior." They then eliminated the response "other" in cases where "other" and one other category were checked and retained the specific response. The remaining nineteen cases were then considered individually and resolved on the basis of retaining the response which the complainant had most emphasized, such as discrediting when making the complaint.

The coders resolved item I-G-2 (complainant's recommended or implied action) by first omitting the responses for "investigation" when it was paired with any other response. They then retained the most serious response in the remaining cases, as a more serious response indicated that preliminary steps had already been completed. Thus, "remove children" was retained over "counsel parents" when both responses were checked for a single case.

The procedure was similar for item IV (agency's initial response to the complainant), as in retaining "place children in foster care" over "accepted for services." The former indicated that the case had already been accepted for service.

Item I-B (situation complained about) again presented more difficulties. Information would be lost by simply checking one category and omitting the other responses; in addition no pattern of responses emerged from a Guttman scale analysis of the complaint 
characteristics. The group resolved this item by treating the categories as separate items which were either checked or not checked. The group had thus created twelve new items. The first (NSIT) indicated the number of responses checked for the case and the second (TSIT) the general type of situation. The remaining ten categories included the seven categories under "neglect" and the former subitems "inadequate parenting," "abuse, " and "abandonment."

\section{LIMITATIONS OF THE DATA}

Limitations of the data indicate restrictions or qualifications regarding the information obtained in the study. The data is limited in several ways. It first of all describes only successful complaints and does not contain information regarding complaint situations which did not result in agency contacts. This limitation was inherent in the procedure of data collection, a procedure which was indicated by considerations of logic, reality, and the intent of the study. It was reasonable to begin by taking cases from the complaint-receiving agencies, realistic in terms of time and logistics, and consistent with the descriptive nature of the study. While the data thus fulfills the intent of the study, it describes only complaint situations which ended in agency contacts.

The descriptive nature of the study and the lack of a control sample reduces the extent to which generalizations can be made 
about factors that produce successful complaints. The study, an initial investigation, aimed at describing the complaint process as evidenced in complaints received at public agencies. The project was not one in which formal hypotheses were drawn up and then tested. Another sample was not gathered in order to compare results with the sample obtained. Inability to determine whether or not the factors discovered would be repeated in other or all successful complaint situations is a limitation of the study. Thus, while the data fulfill: the nature and intent of the study, the methodology used to collect the data and the type of data obtained reduce the confidence with which we can generalize to the population as a whole.

The data evidences a relative size limitation ( $N$ equals 101 ). While not excessively small for the initial investigative type of project involved, the sample is of a size which necessitates caution in its use. Several items (II-C-2, II-D-2, II-E-2, II-F-1, and II-F -2) within the sample contain data from an even smaller $N$, as the categories were not applicable for a majority of the cases obtained. The data from these items is more limited because of the reduced size of the sample.

The data is also subject to a reporting limitation. One factor may be the seasonal nature of the sample, for complaints may be more or less prevalent or of a different type in the winter months as opposed to summer. It is known, for example, that during the 
summer months after the school year is over, working mothers frequently make changes in their child care arrangements, and the Women's Protective Division indicated that casual child carearrangements become a problem to them as the summer progresses. A different sampling limitation involves the actual reporting of the data. An attempt was made to obtain every complaint lodged at the various agencies for the period of the study. There were indications, however, that some sample was lost. The data should have included, for example, a duplicate case from the Women's Protective Division for every case received at Shelter Care because of the nature of the functioning of those two divisions. The absence of duplicate cases in each instance indicates that some data was not reported. We are unable to indicate whether this difficulty was a random lack of reporting or some systematic bias in the reporting procedure. Nor are we able to say with certainty exactly how extensive was the reporting loss or of what kind. There is every indication, however, that this loss, while unknown, was small and probably does not exceed 10 per cent. A loss of this size appears not to invalidate the project or the conclusions reached from the data obtained.

The data is subject to a measurement limitation. While the measures used in the project were appropriate to the nature and intent of the study and the data obtained, they were necessarily of a crude nature. The schedule used was composed of nominal items 
with a few ordinal ones and the measurement scales corresponded to the items. The statistical tests used were non-parametric, since the items and the scales were nominal or ordinal at best. The measurement problem was dealt with by the use of coder ratings for which reasonably high reliabilities were obtained.

The data is also limited in that the plan of analysis did not control for factors that may have influenced the complaint process. The study obtained no information regarding such factors as age, race, religion, and socio-economic status of either the complainant or the person complained about. The data does not show, for example, whether complaints were more likely to be made by white, AngloSaxon protestants or by Negro, middle-class, white-collar workers. There is thus no way to indicate whether the data is from a cross section of the population or from a certain segment which tends to become involved with public agencies. Since the data does not indicate social, cultural, and economic factors, it cannot indicate the possibility of different types of complaint processes or differing methods of resolving child care problems which may exist in different subgroups.

\section{VALIDITY OF THE DATA}

Considering the objectives of the study, little could be done to establish the convergent or construct validity of all measurements. 
The project attempted to gather and describe information relating to the complaint process through complaints received at public agencies. The objective and the method of data collection ruled out establishing for all the factors the type of validity described by Campbell and Fiske (1959) or by Cronbach and Meehl (1955). In spite of these cautions as to the data as a whole, there are certain facts which we can indicate regarding the problem of validity. It is apparent that some confidence can be placed in the key variables. Relationships were discovered among these variables according to patterns which we might expect. Abuse cases, for example, were rated more serious while "neglect only" cases tended to be rated less serious (see Chapter IV).

The data made sense in terms of describing relationships of the collected evidence. Various statistical measures produced results which corresponded to the expected relationships. Nonparametric tests (chi square, phi, gamma, and Yule's Q) were used to assess the relationship between the key variables and produced a type of construct validity for those relationships. See Chapters III and IV for specific conclusions regarding the relationships tested. However, the matrix of correlations (gammas and Yule's Q's) shown in Table $\mathrm{V}$ reveals the convergence of similar variables with high correlations (in the triangle) discriminated from the less highly correlated variables of the complaint process (in the square). 
MATRIX OF CORRELATIONS DISCRIMINATING FOR TYPE OF COMPLAINT SITUATION (TSIT), SERIOUSNESS OF SITUATION (SOS),

AND CHILD CARE ARRANGEMENT (ARNG) BY DISCREDITING INFORMATION (DISC), STRENGTH OF DISCREDITING

EVIDENCE (EVID), AND MOTIVATION FOR COMPLAINT (MOTV)

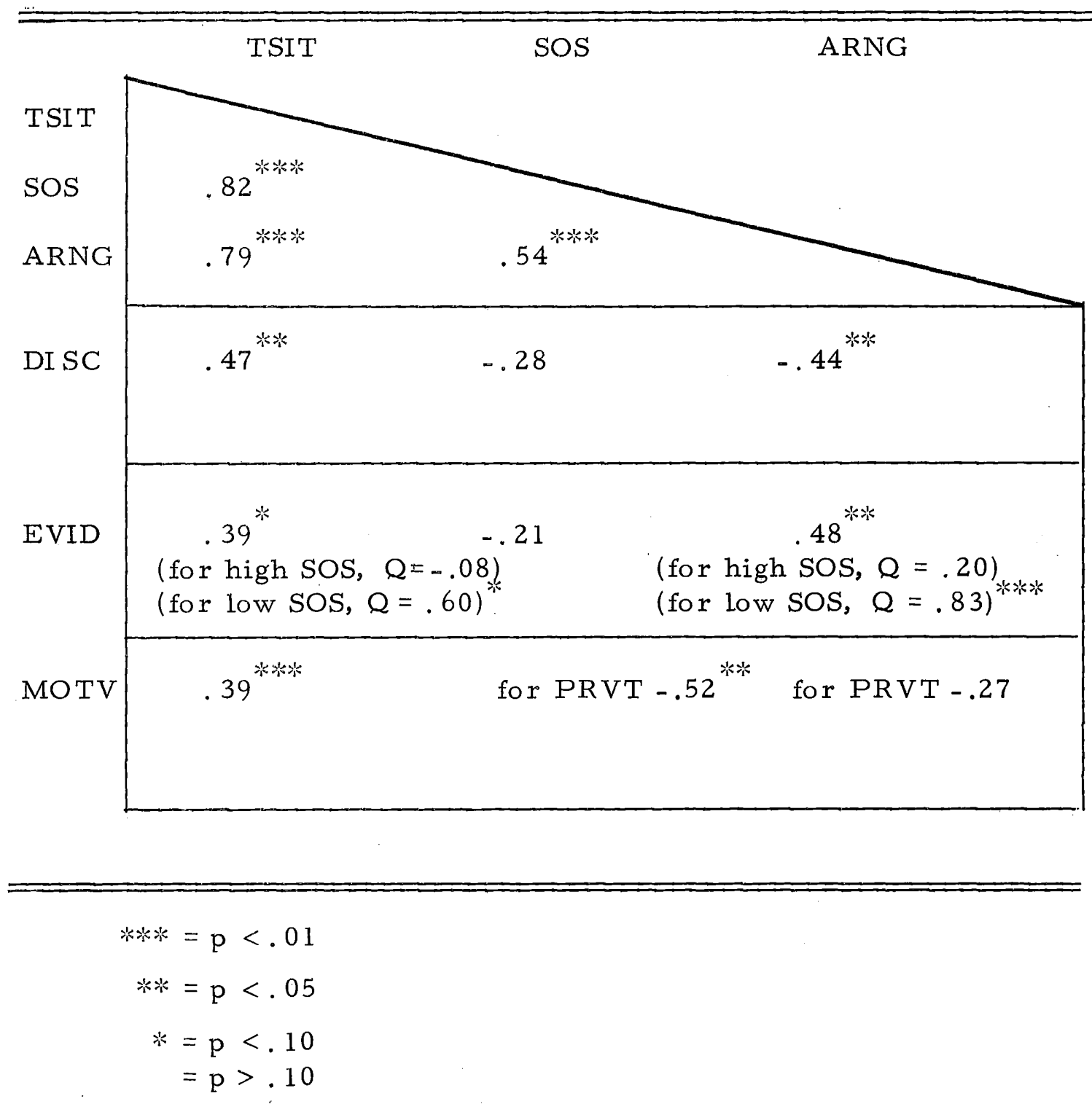


The type of test indicated in Table $\mathrm{V}$ produced relationships which coincided with the best sense of the data. Within the framework of the problem of validity the convergence of these two facts indicates a type of validity in accord with the recoded data. The fact that within this framework it was possible to make good theoretical sense of the correlations, is perhaps the best evidence of the validity of the data. 


\section{FINDINGS: DESCRIPTION OF COMPLAINT PROCESS}

This chapter describes the complaint process from the complainant's response to the complaint situation to the disposition by the agency. The chapter is divided into four parts. Each part presents questions which served as guides in analyzing the data.

The first section describes the kinds of situations people report. A classification is presented that was developed from the common characteristics in the complaints. Complaints were then rated as to the degree of seriousness. Case examples illustrate the types of complaint situations and the degree of seriousness involved.

The next section describes the complainants with respect to their relationships to the family and their experience with the situation reported.

The third section examines the complainant's choice of a protective service agency. The responses of the agencies are also considered.

The final section describes what is involved in making the complaint. Attention is focused on the channels of communication, the motivation of the complainant, and the efforts on the part of the 
complainant to communicate a plausible complaint.

\section{COMPLAINT SITUATIONS}

In considering what types of situations people make protective service complaints about, several questions were posed as guides.

(1) What are the most frequently reported characteristics of complaint situations?

(2) Based on these characteristics, are there different types of complaint situations?

(3) How serious are these situations for the child?

(4) Was a breakdown in or a lack of a child care arrangement involved in the complaint situation?

The characteristics of the complaint situations and their frequency of mention were:

Inadequate Supervision $\quad 52$

Abuse 32

Immoral Behavior 24

Lack of Medical Care 22

Lack of Sufficient Food 20

Unsafe or Unsanitary Living Conditions 15

Emotional Neglect 12

Inadequate Clothing $\quad 11$

Abandonment 7

Inadequate Parenting due to

\begin{tabular}{lr} 
Physical or Mental Illness & 6 \\
\hline Total & 201
\end{tabular} 
It was possible to simplify this data, however, assigning each complaint to one of three mutually exclusive categories: abuse, neglect, inadequate supervision. There were five mixed cases which involved abuse and inadequate supervision. These were classified in the abuse category, since abuse and inadequate supervision were distinct from each other in most cases; thus "abuse" means any mention of abuse. Next, the remaining forty-seven inadequate supervision cases were treated as one group even though thirty of these involved some mention of other complaint characteristics, with the exception of abuse. Then, having separated out abuse and inadequate supervision, the remainder, all of which reflected some aspect of neglect, were classified as neglect. "Neglect," then, means neglect only without abuse or inadequate supervision. The typological distribution was:

\begin{tabular}{lr} 
Abuse & 32 \\
Neglect & 22 \\
Inadequate Supervision & 47 \\
\hline Total & 101
\end{tabular}

The following vignettes serve to illustrate the type of situations described by the classification.

$\underline{\text { Abuse }}$

Children's Department of welfare received a call from another welfare department regarding an abuse situation. The mother of a five year old girl was reportedly lifting the child up by her shoulders and hitting her against the wall and lifting 
her up by her hair and striking her in the face. This situation was learned about when the child's grandmother felt she could no longer tolerate the child receiving this kind of treatment for fear she would die. The grandmother hesitated to become involved in making an official complaint as she was afraid the mother might kill her in revenge. She therefore told her own caseworker who made the complaint in her behalf.

\section{Neglect}

A neighbor phoned the Police Bureau to report that a ten week old girl was wet and dirty, and she appeared to be unhealthy and sick. Her coloring was bad and the skin on her arms seemed to hang. She was painfully thin. The complainant had talked to the mother about the child's eating and was told the baby was allergic to cow's milk and soy bean milk, so her diet consisted of carrot juice and bits of food from the table. The apartment was described as very untidy. The neighbor hoped the police would make a visit to see if the infant could be helped in some way.

Inadequate Supervision

The Sheriff's office phoned the Welfare Commission to report that six children, ages one to fifteen, were left alone in a very filthy house with no food. The children were very dirty and appeared to be ill. The Sheriff's deputies picked the children up and placed them in a shelter care home, where it was discovered they all had scabies and the baby had impetigo.

Most cases contained one or two characteristics, but the total distribution was: 
Number of

Characteristics

Mentioned

\begin{tabular}{rr}
1 & 44 \\
2 & 27 \\
3 & 20 \\
4 & 8 \\
5 & 1 \\
6 & 0 \\
7 & 1 \\
\hline Total & 101
\end{tabular}

Number

of

Cases

4 (2)

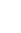

01

The following case example will illustrate this situation.

\section{Abuse with neglect}

A neighbor became concerned for the welfare of five children, ages one to ten, who were often left alone and were without sufficient food. She discussed this with another neighbor and then decided to phone the Sheriff's office. Her complaint included the following information: the children were often left by themselves for the whole day and sometimes longer, the baby had a badly bloated stomach, all the children got sick after being fed, the children told the neighbor the baby was fed only sugar water, the children frequently have impetigo, medical and dental care are provided only when the mother is receiving as sistance from welfare. The children have been 'kissed, felt and fingered, and played around with, by men friends of the mother." This situation had been occurring for close to two years, since the mother and father separated.

On the basis of the alleged sexual molestation, this case was classified as an abuse case. It illustrates borderline situations in which some element of both abuse and neglect were reported but the case was classified in the abuse category.

To deal with the third question proposed, "How serious are 
these situations for the child?" it was necessary to define what was meant by seriousness.

It was recognized that all of these situations involved some risk to the child and were therefore considered serious; however, some of the cases in the sample were obviously more serious in nature than others. Therefore, the variable seriousness was sub-divided into the following categories: marginal, moderate, serious, and very serious. To simplify the data, the categories of marginal and moderate were combined and dealt with as "low serious," while categories of serious and very serious were combined and dealt with as "high serious." Low seriousness was used to describe situations which appeared to be detrimental, but not necessarily harmful, to the child. On the other end of the continuum, high seriousness was used when a situation appeared to endanger the child's life or involved some physical or mental damage to the child. Although this determination was a global judgment, it reflected an attempt to as sess the probable effects on the child as objectively as possible.

\section{Low serious}

The Women's Protective Division contacted the Shelter Care unit of the Welfare Commission to report a small child who had been brought to the Women's Protective Division by the officer who arrested both her parents on an extortion charge. She was detained at the Women's Protective Division for three hours because the parents thought one of them might be bailed out. Because the child was crying and it did not look like either parent would be out that evening, she was placed at 
Waverly. The child had on dirty clothes but seemed other wise adequately cared for.

\section{High serious}

A neighbor phoned the Children's Department of Welfare to report that five minor children, ages three weeks through nine years, were being physically neglected. The neighbor reported that the children were hungry and poorly clothed. The parents of the children were unemployed and did not obtain medical care for the children. The three week old baby was given only water to drink. The neighbor was afraid that the baby would die if she did not receive the care she needed.

Table VI shows the rated degree of seriousness of the cases

by the type of complaint situation.

TABLE VI

SERIOUSNESS OF SITUATION BY TYPE OF COMPLAINT SITUATION FOR TOTAL SAMPLE

\begin{tabular}{|c|c|c|c|c|}
\hline \multirow[b]{2}{*}{ Seriousness } & \multicolumn{3}{|c|}{ Type of Situation } & \multirow[b]{2}{*}{ Total } \\
\hline & Abuse & Neglect & $\begin{array}{c}\text { Inadequate } \\
\text { Supervision }\end{array}$ & \\
\hline Low & 3 & 15 & 38 & 56 \\
\hline High & 29 & 7 & 9 & 45 \\
\hline Total & 32 & 22 & 47 & 101 \\
\hline $\begin{array}{l}{ }^{1} \text { Gamn } \\
\text { used for all } \\
\text { magnitude of } \\
\text { tables show }\end{array}$ & $\begin{array}{l}\text { or its } \\
\text { es to } p \\
\text { elatior } \\
\text { arviline }\end{array}$ & $\begin{array}{l}\text { ent for th } \\
\text { compara } \\
\text { tween va } \\
\text { tionship }\end{array}$ & $\begin{array}{l}\text { x } 2 \text { table, } Y \\
\text { y of measur } \\
\text { les. Many } \\
\text { corner corr }\end{array}$ & $\begin{array}{l}\text { 2) is } \\
\text { of the } \\
2 \times 2 \\
\text { " and }\end{array}$ \\
\hline
\end{tabular}


As might be expected, a high correlation between the type of situation and the degree of seriousness was found. This is the case because of the rationale used in determining the degree of seriousness. That is, seriousness was rated higher when the child was in danger in a way that threatened his life. This is the reason that most of the abuse cases appear as high in regard to seriousness.

To complete the description of what is complained about, attention was directed to these equations. What part, if any, did a breakdown in or lack of a child care arrangement play in the complaint process? How serious were those situations where a breakdown occurred?

It was suspected that some substitute child care arrangements made by mothers for working, training, or other reasons are characterized by instability, and the breakdown of these arrangements sometimes leads to shelter care referrals or protective service complaints to community agencies. This study found 47 per cent of all cases involved a breakdown in or a lack of a child care arrangement. Of this 47 per cent, which involved a breakdown in or lack of a child care arrangement, the following reasons for this situation

thus Yule's $Q$ is applicable while phi is not. Phi is shown where applicable. Chi square provides the basis for showing the significance level for a distribution. All chi squares reported for $2 \times 2$ tables are corrected for continuity using the Yate's correction. 
were given:

$20.5 \%$ breakdown in existing arrangements

50. $0 \%$ failure to make an arrangement

$25.0 \%$ inadequate arrangements

4. 5\% previous arrangement broke down and no new arrangemeñt made

$\overline{100.0 \%} \quad \mathrm{~N}=47$

One type of complaint appeared most likely to have been pre-

cipitated by a breakdown in or a lack of child care arrangement, that is, complaints about inadequate supervision. Table VII shows, according to the type of complaint situation, whether or not there was a breakdown in or a lack of child care arrangements.

TABLE VII

CHILD CARE ARRANGEMENT BY TYPE OF COMPLAINT SITUATION FOR TOTAL SAMPLE (PERCENTAGES)

\begin{tabular}{lcccc}
\hline \hline & \multicolumn{3}{c}{ Type of Situation } \\
\cline { 2 - 5 } Child Care & Abuse & Neglect & $\begin{array}{c}\text { Inadequate } \\
\text { Supervision }\end{array}$ & Total \\
\hline $\begin{array}{l}\text { Breakdown or } \\
\text { Lack of } \\
\text { Arrangement }\end{array}$ & 16 & 29 & 77 & 47 \\
$\begin{array}{l}\text { No Breakdown or } \\
\text { Lack of } \\
\text { Arrangement }\end{array}$ & 84 & & & \\
& $100 \%$ & $100 \%$ & $100 \%$ & $100 \%$ \\
Total & $\mathrm{N}=32$ & $\mathrm{~N}=22$ & $\mathrm{~N}=47$ & $\mathrm{~N}=101$ \\
\end{tabular}

$\left(\gamma=.79 ; x^{2}=32.64,2 \mathrm{df}, \mathrm{p}<.001\right)$ 
The high incidence of breakdown in the category of inadequate supervision suggests the question, Would these situations have been referred if it were not for the breakdown in or lack of a child care arrangement?

The degree of seriousness of those cases where a breakdown or a lack of child care arrangement occurred is shown in Table VIII. It was found that the more serious cases tended to be those where there was no breakdown in or lack of child care arrangement. The less serious cases tended to be situations involving a breakdown in or lack of child care: arrangement. This is not surprising and only confirms what was found above. It is emphasized here because these relationships become important in arriving at a typology of complaint processes.

TABLE VIII

\section{CHILD CARE ARRANGEMENT BY SERIOUSNESS OF SITUATION FOR TOTAL SAMPLE}

\begin{tabular}{lccc}
\hline & \multicolumn{2}{c}{ Seriousness } & Total \\
\cline { 2 - 4 } \multicolumn{1}{c}{ Child Care } & & High & \\
\hline $\begin{array}{l}\text { Breakdown or } \\
\text { Lack of }\end{array}$ & 33 & 14 & 47 \\
Arrangement & & & \\
$\begin{array}{l}\text { No Breakdown or } \\
\text { Lack of }\end{array}$ & 23 & 31 & 54 \\
Arrangement & 56 & 45 & 101 \\
\hline Total & & & \\
\hline \hline
\end{tabular}

$$
\text { (Yule's } Q=.54 ; \phi=.29 ; \chi^{2}=7.17,1 \mathrm{df}, \mathrm{p}<.01 \text { ) }
$$




\section{THE COMPLAINANT}

Situations complained about have been described and consideration is now given to who makes these complaints. In looking at this aspect of the complaint process, the following questions were considered:

(1) Who are the complainants? Are they relatives of the family or non-relatives, or are they social agency personnel?

(2) How did they know about the situations? Did they observe it themselves or were they told about it by someone else?

(3) How long had they known about the situations?

(4) Does the relationship of the family to the complainant influence the type of situation he will report?

(5) Had the complainant ever cared for the children involved in the complaint?

In looking at who made the complaint, it was found that 69 per cent of the complaints came from the private sector of the commu:nity, while 31 per cent came from agency personnel. The relationship of the complainant to the family resulted in the following frequencies by cases:

\begin{tabular}{lr} 
Relatives & 18 \\
Non-relatives & 43 \\
Unknown & 9 \\
Agency personnel & 31 \\
\hline Total & 101
\end{tabular}


It was thought that there might be differences between relatives and non-relatives as to who complained about what type of situation; however, no differences were found. Except for agencies referring abuse cases to the Juvenile Court, the relationship of the complainant to the family had no bearing on the type of situation reported.

The complainant's experience with the complaint situation was investigated to determine how the complainant knew about the situation. Did he actually observe the situation or was he told about it by someone else? Table IX shows how the complainant knew about the situation. The information is presented for both the private sector, which is comprised of relatives and non-relatives, and for agency personnel. It may be seen that, in general, complainants had first hand observational knowledge of the situations they complained about, but this was less true of agency personnel whose complaints were in the nature of referrals to other agencies based on indirect information.

A second factor of the complainant's experience with the situation was how long he had known about the situation prior to making the complaint. It was discovered that complainants were not apt to report a situation which was an isolated incident, as exemplified by the fact that there were only fifteen cases in which this occurred. In attempting to interpret this information, certain questions were raised. (1) Does this reflect the reluctance of people to make a 
TABLE IX

COMPLAINANT'S KNOW LEDGE OF COMPLAINT SITUATION BY SOURCE OF COMPLAINT FOR TOTAL SAMPLE

\begin{tabular}{lccc}
\hline $\begin{array}{l}\text { Knowledge of } \\
\text { Complaint } \\
\text { Situation }\end{array}$ & \multicolumn{2}{c}{ Source of Complaint } & \\
\cline { 2 - 4 } Observed & 41 & Agency & Total \\
Informed & 6 & 20 & 61 \\
\hline Total & 47 & 11 & 17 \\
\hline \hline
\end{tabular}

(unknown $=23 ; \gamma=.58 ; x^{2}=5.40,1 \mathrm{df}, \mathrm{p}<.05$ )

complaint unless they have repeated experience with the situation?

(2) Must the situation be observed repeatedly before the complainant can interpret it as being serious enough to warrant a formal complaint?

A third factor of the complainant's experience with the situa:tion was whether or not the complainant had ever cared for the child. It was found that 93 per cent of relative complainants had cared for the child in the past, while 25 per cent of non-relative complainants had cared for the child in the past. In 12 per cent of the cases, the complainant was caring for the child at the time the complaint was made. 
III. COMPLAINANTS' USE OF PROTECTIVE SERVICE AGENCIES

Having identified the complainant, attention was focused on the question of whether the relationship of the complainant to the family was associated with the agency to which the complaint was made. There was no difference between complainant groups with respect to the agency to which they made their complaint. Relatives and nonrelatives used the various agencies from which this information was obtained, with the following distribution:

\begin{tabular}{lr} 
Women's Protective Division & 56 \\
Welfare (Shelter Care, Family & \\
Services and Children's & \\
Department) & 37 \\
Juvenile Court & 8 \\
\hline Total & 101
\end{tabular}

It was thought that some agencies might tend to receive more serious cases than others. However, the degree of seriousness of the situations showed no clear association with the agency to which complaints were made. The distribution of cases to agencies, by seriousness, may be seen in Table $X$. 
TABLE $X$

\section{SERIOUSNESS OF SITUATION BY AGENCY INVOLVED FOR TOTAL SAMPLE}

\begin{tabular}{lcccc}
\hline \hline & \multicolumn{3}{c}{ Agencies } & \\
\cline { 2 - 5 } Seriousness & WPD & Welfare & $\begin{array}{c}\text { Juvenile } \\
\text { Court }\end{array}$ & Total \\
\hline Low & 33 & 18 & 5 & 56 \\
High & 23 & 19 & 3 & 45 \\
\hline Total & 56 & 37 & 8 & 101 \\
\hline \hline & $(\gamma=.11 ;$ & $\left.\chi^{2}=1.13,2 \mathrm{df}, \mathrm{p}<.70\right)$ & &
\end{tabular}

Another area of particular interest was to see what action was suggested by the complainant regarding his complaint. The frequency of suggestions made by the complainants was:

\begin{tabular}{lr} 
No suggestion & 45 \\
Investigation & 25 \\
Counsel parents & 2 \\
Coerce parents & 3 \\
Place child with friend or relative & 4 \\
Remove child from home & 4 \\
Other & 5 \\
Unknown & 13 \\
\hline Total & 101
\end{tabular}

The five suggestions in the "other" category suggested such things as request for some kind of help for the mother and insistence on the part of the complainant that his name be given to the family complained about. 
It was found that 45 per cent of all complainants did not make a suggestion. Twenty-five per cent of the complainants suggested that an investigation be made into the situation they were reporting.

After looking at the recommended action, it was questioned if there would be a difference between the recommended action to the agency and the services given by the agency. It was thought this would be an indication of the community's knowledge of agency services. It was further questioned if there would be any difference in the service given to relatives as opposed to non-relatives.

The action taken by the agencies can be summarized in the following way: Eighteen per cent of the complaints resulted in children being placed outside their own home, and an additional 75 per cent of the complaints were at least accepted for service and investigated. Eight per cent of the complaints were not accepted for service.

There were no differences in services given to relatives as compared to non-relatives of the family involved in the complaint. The type of service given by the agency was the same in both cases. It is interesting to note that in only 8 percent of the referrals did the complainant recommend that the child be placed, while in actuality, 18 per cent of the complaints resulted in the children being placed. 


\section{ESSENTIAL ELEMENTS OF A SUCCESSFUL COMPLAINT PROCESS}

The types of situations reported have been described, the complainants have been identified, and the services recommended to the agencies as well as the services rendered by the agencies, have been discussed. Now in further identification of elements involved in making a successful complaint, attention is turned to questions of motivation and social aspects of communicating the complaint.

There is some indication that complainants need to have some kind of social confirmation and support for making a complaint. It was as sumed that complainants would confirm what they observe and what they judge about the complaint situation and elicit support for taking the complaint action by discussing the complaint with others. This social confirmation may be obtained through informal social contacts with family and neighbors. In support of this supposition, an attempt was made to obtain specific information as to whether or not the complainant discussed the situation with someone prior to making a complaint. This information was not always available, however, and had to be obtained solely on the basis of whether or not the agency receiving the complaint had any evidence of the complainant having discussed the situation. In many cases this information was not obtained by the agencies as this was not a regular procedure in their accepting a complaint referral. 
The validity of the assumption that complainants will seek social confirmation prior to making the complaint is therefore ham:pered by this lack of specific information. Despite the limitations in the data, this sample reveals that half the complainants were re:ported to have discussed the situation with someone before making the complaint. It was salient enough to be mentioned by the agency receiving the referral. Therefore, this suggests that discussion of the complaint probably was more prevalent than the data suggested.

There was a sharp difference between the Women's Protective Division and the other agencies as to whether prior discussion of the complaint situation with others was reported. This can be seen in Table XI. Since the seriousness of the situations did not significantly differ by agency, it seems likely that the agency-linked difference in reported prior discussion reflects characteristics of the complaintreporting process in agencies.

TABLE XI

DISCUSSION OF SITUATION PRIOR TO COMPLAINING BY AGENCY INVOLVED FOR TOTAL SAMPLE

\begin{tabular}{|c|c|c|c|}
\hline \multirow[b]{2}{*}{ Discussion } & \multicolumn{2}{|c|}{ Agencies } & \multirow[b]{2}{*}{ Tota } \\
\hline & WPD & Other Agencies & \\
\hline Yes & 14 & 36 & 50 \\
\hline No, Unknown & 42 & 9 & 51 \\
\hline Total & 56 & 45 & 101 \\
\hline
\end{tabular}

$\left(\gamma=-.79 ; \phi=.54 ; x^{2}=29.44,1 \mathrm{df}, \mathrm{p}<.001\right)$ 
Interesting relationships were found between the discussion of the situation complained about and the type of complaint situation. This suggests a greater need to discuss neglect, and the least likelihood of discussing inadequate supervision, with the abuse situations falling somewhere in between. See Table XII.

TABLE XII

DISCUSSION OF SITUATION PRIOR TO COMPLAINING BY TYPE OF COMPLAINT SITUATION FOR TOTAL SAMPLE

\begin{tabular}{lcccc}
\hline \hline & \multicolumn{3}{c}{ Type of Situation } \\
\cline { 2 - 5 } Discussion & Abuse & Neglect & $\begin{array}{c}\text { Inadequate } \\
\text { Supervision }\end{array}$ & Total \\
\hline Yes & 19 & 15 & 16 & 50 \\
No, Unknown & 13 & 7 & 31 & 51 \\
\hline Total & 32 & 22 & 47 & 101 \\
\hline \hline
\end{tabular}

$$
\left(\gamma=.47 ; \chi^{2}=4.50,2 \mathrm{df}, \mathrm{p}<.20\right)
$$

This information suggests the following possible interpretations. The more problematic the complaint situation is in terms of the complainant's ability to directly observe and interpret the situation and report that discussion in presenting the complaint to an agency, the more likely he is to discuss it with someone prior to making the complaint and to report that discussion as support of the complaint. In contrast would be a situation in which a child is not 
supervised, the presence or absence of someone to care for the child is readily verifiable, and the norms are probably clear that the child needs to be supervised. Likewise, abuse is more dramatically obvious, and the danger to the child is not difficult to interpret. Complainants can have assurance that their complaints will be verified and appear plausible in the case of either inadequate supervision, although less serious, or the case of abuse, which is more serious. This appeared to be the case, regardless of the complainant's relationship to the family.

This phenomenon of seeking social confirmation and support, prior to making the complaint, may be seen in the following vignette.

The original complaint on the $\mathrm{S}$. case was made by grandparents who resided out of state. They requested an investigation of the situation of a ten week old girl and a two year old boy who they feared were not receiving proper care. The grandparents had been caring for the little boy before the parents moved to Portland. Prior to this move they discovered the little girl had severe diaper rash which required medical attention. They directed a letter to the Portland Police Bureau and the Multnomah County Welfare Commission, requesting information about the children's welfare. Women's Protective Division (WPD) visited the family and felt the situation required intervention. WPD requested the visiting health nurse see the family, as medical care appeared to be needed. About the same time, a second report was received by WPD from a women who learned from her own sister that the $S$. children were not receiving adequate care. This information was forwarded to the Visiting Nurse Association, who in turn called upon the family. The nurse found the mother to be very ignorant regarding the care of the infant who appeared to be malnourished and in need of immediate medical care. This report was given to $W P D$, who made a referral to the Juvenile Court. The Juvenile Court counselor contacted the mother and suggested the child be taken to a doctor. The child was 
admitted to a hospital and upon its release the mother was willing to receive help from the health nurse. No further court action was taken as the Juvenile Court left responsibility with WPD and the visiting nurse to see that the mother followed the medical regimen.

Figure 1 illustrates the communication network in the above case. All the contacts shown above the dotted line represent those made at the neighborhood or community level and all those below are at the agency level. The figure is numbered in the order in which people or agencies were consulted with "F" standing for feedback.

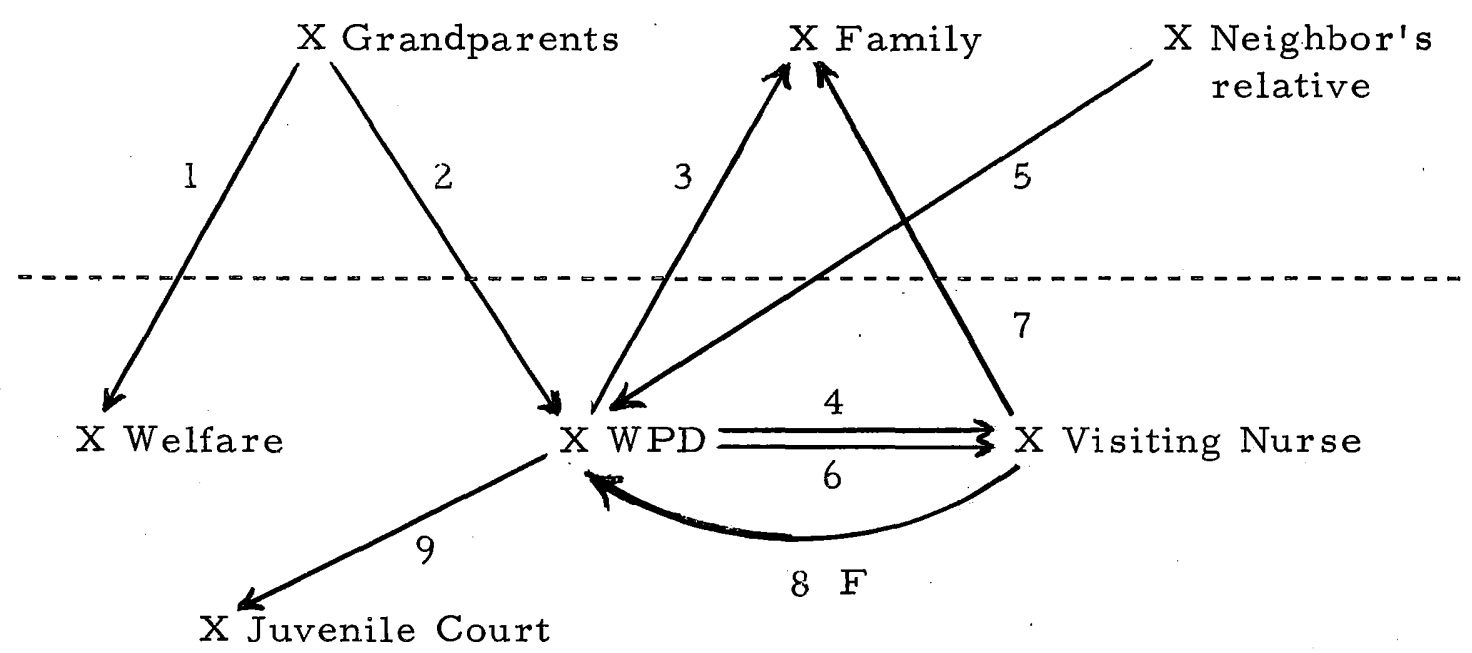

Figure 1. Communication network illustrating contacts among community and agencies.

This case is an example of the communication pattern between community and agencies with no known contacts within the community. However, there are numerous contacts among the agencies, an example of multiple agency cooperation. 
The next case example illustrates contacts between people in

the community. Contacts between the agencies are for referral only.

Mr. B. and his wife had separated, just prior to this complaint. Mr. B. returned to the home to get some of his clothing, and found his two daughters in the care of his nineteen year old brother-in-law who was allegedly drunk. While looking for his clothing, Mr. B. reportedly found a dirty diaper which contained both feces and maggots. His two daughters were outside playing in the rain and were not properly clothed. He left the home and discussed this situation with a friend. Mr. B. then called WPD to lodge a complaint. In the course of the investigation, WPD requested Mr. B.'s parents accept responsibility for the children but they refused. WPD then placed the children in shelter care.

This is illustrated in Figure 2.

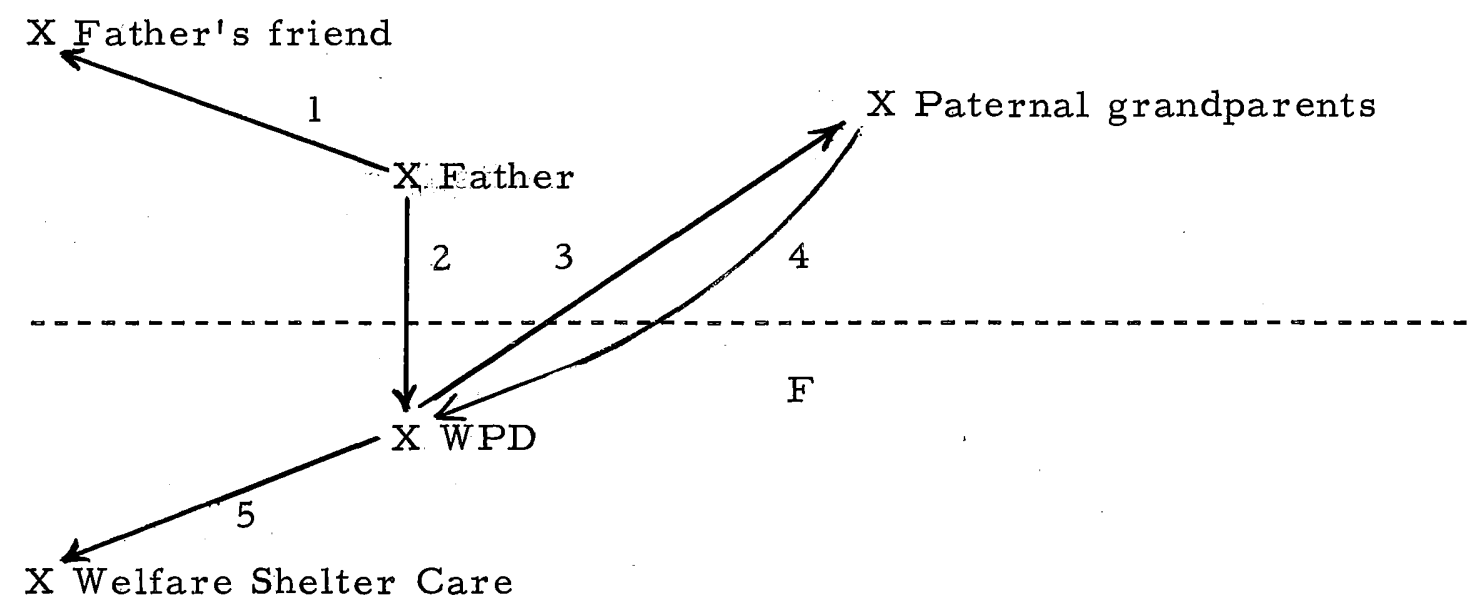

Figure 2. Communication network illustrating contacts between people at community level.

The information given by the complainant indicated his motivation for making the complaint and his need to legitimize this action. These were two separate processes; the first to be dealt with is the complainant's motivation for making the complaint. To study this 
variable, the sample was divided into three categories of motivation: concern for child, mixed concern, and self concern. Concern for the child was indicated when the complainant appeared to be solely interested in the welfare of the child. Mixed concern was identified when the motives indicated in the complaint showed a concern for the child's welfare as well as for the complainant's own interests. Self concern was indicated when the complainant's motivation appeared to be solely for his own interests. The following brief vignettes will serve to illustrate these ratings.

Motivation--child concern

Mrs. F. called WPD to report that she had seen Mrs. D. kicking her son in the front yard of her home. She told Mrs. D. to stop, and Mrs. D. stated that he was her child, and she could kick him if she "damned pleased." The child was screaming, and had been knocked to the ground. The child often played in the neighborhood but Mrs. F. had not seen Mrs. D. come after him before. When questioned about her reason.for calling at that time, Mrs. F. stated that she was so distraught that she could not sleep for thinking about it, so called police the following morning.

\section{Motivation - - mixed concern}

A neighbor complained that the children next door were always crying and didn't seem to be happy. She felt the children were either ill or hungry and was concerned about the mother's care of the children. The children were dirty and undisciplined. The complainant explained that she could not stand by without saying something about the behavior and condition of the children. She felt something must be done and, "besides, the kids are running through my yard and flowers all the time." 
$\underline{\text { Motivation--self concern }}$

Mrs. M. called WPD, at six in the morning, to report a seven year old boy who stayed up until all hours of the night roaming the neighborhood. She reported that he was sometimes alone but was often with the older boys in the area. She reported that she had seen him breaking bottles in the street and smoking. The complainant stated her reason for calling at this time was that "this boy has kept me awake all night and I did not get any sleep."

Using the above described and illustrated classification of motivation, the following frequency distribution was obtained.

$58 \%$ child motivated

$29 \%$ mixed motivation

$13 \%$ self motivated

It was found that complaints made by relatives tended to be based on mixed motivation, while the complaints rated as self motivated tended to be made by non-relatives. All but one of the complaints clasified as self: motivated were made by non-relatives. This is shown in Table XIII.

The complainant's motivation was then examined, taking the following additional variables into consideration: type of situation reported, breakdown in or lack of child care arrangement, serious ness of the situation. It was found that there was a relationship between motivation and type of situation. In cases of abuse and neglect, information given by the complainant indicated a concern for the child. See Table XIV. 
TABLE XIII

MOTIVATION FOR MAKING COMPLAINTS BY COMPLAINANT'S

RELATIONSHIP TO FAMILY FOR PRIVATE SECTOR OF COMMUNITY

\begin{tabular}{lccc}
\hline \hline \multirow{2}{*}{ Motivation } & \multicolumn{2}{c}{ Relationship } & Total \\
\cline { 2 - 4 } Child & 6 & Ron-relative & 21 \\
Mixed & 10 & 16 & 26 \\
Self & 1 & 10 & 11 \\
\hline Total & 17 & 41 & 58 \\
\hline
\end{tabular}

(unknown $=12 ; y=.42 ; x^{2}=3.194,12 \mathrm{df}, \mathrm{p}<.30$ )

TABLE XIV

MOTIVATION FOR MAKING COMPLAINTS BY TYPE OF COMPLAINT SITUATION FOR TOTAL SAMPLE

\begin{tabular}{lcccc}
\hline \hline & \multicolumn{3}{c}{ Type of Situation } \\
\cline { 2 - 5 } Motivation & Abuse & Neglect & $\begin{array}{c}\text { Inadequate } \\
\text { Supervision }\end{array}$ & Total \\
\hline Child & 25 & 11 & 20 & 56 \\
Mixed & 7 & 4 & 17 & 28 \\
Self & 0 & 6 & 6 & 12 \\
\hline Total & 32 & 21 & 43 & 96 \\
\hline \hline
\end{tabular}

(unknown $=5 ; \quad \gamma=.39 ; \quad x^{2}=14.60,4 \mathrm{df}, \mathrm{p}<.01$ ) 
When a breakdown in or a lack of a child care arrangement was reported, two-thirds of the complainants were rated as being mixed or self motivated. This category would include complaints by babysitters who would no longer care for the child because the parent failed to return at the specified time and babysitters who were not paid. Also included were complaints by persons who had been bothered by unsupervised children. See Table XV.

TABLE XV

MOTIVATION FOR MAKING COMPLAINTS BY WHETHER THERE WAS A BREAKDOWN IN OR LACK OF A CHILD CARE ARRANGEMENT AS A PART OF COMPLAINT SITUATION FOR PRIVATE SECTOR OF COMMUNITY

\begin{tabular}{lccr}
\hline \hline & \multicolumn{2}{c}{ Child Care } & \\
\cline { 2 - 4 } Motivation & $\begin{array}{c}\text { Breakdown in } \\
\text { or Lack of } \\
\text { Arrangement }\end{array}$ & $\begin{array}{c}\text { No Breakdown in } \\
\text { or Lack of } \\
\text { Arrangement }\end{array}$ & Total \\
\hline Child & 8 & 18 & 26 \\
Mixed or Self & 17 & 22 & 39 \\
\hline Total & 25 & 40 & 65 \\
\hline \hline
\end{tabular}

(unknown $=5 ;$ Yule's $\mathrm{Q}=.27 ; \chi^{2}=.61,1 \mathrm{df}, \mathrm{p}<.50$ )

As would be expected, there was a relationship between the ratings or motivation for making the complaint and seriousness of the situation. This is shown in Table XVI. Agency personnel were excluded from this analysis. 
TABLE XVI

MOTIVATION FOR MAKING COMPLAINTS BY SERIOUSNESS OF SITUATION FOR PRIVATE SECTOR OF COMMUNITY

\begin{tabular}{lccc}
\hline \multirow{2}{*}{ Motivation } & \multicolumn{2}{c}{ Seriousness } & Total \\
\cline { 2 - 4 } Child & Low & 17 & 26 \\
Mixed or Self & 25 & 15 & 40 \\
& & & 66 \\
\hline
\end{tabular}

(unknown $=4 ;$ Yule's $Q=-.52 ; \chi^{2}=3.85,1 \mathrm{df}, \mathrm{p}<.05$ )

Having discussed motivation, attention is now focused on the second process identified through the actual wording of the complaint, the complainant's need to legitimize his action. There was at least some evidence of the complainant discrediting the parents of the child in 98 per cent of the cases reported. This almost universal tendency would occur when evidence of deviant or socially unacceptable behavior was given to legitimize the complaint, rather than evidence that would actually support the specific charges being made. Garfinkel's (1956) article, "Conditions of Successful Degradation Ceremonies," discusses the conditions of identity and status degradation. The protective service referral has similarities to moral condemnation, which is one element of degradation ceremonies. Most of the 
referrals contained information that discredits the parents as incompetent, thereby attempting to increase the plausibility that they would neglect or abuse their child. This is not to imply that the complainant's motivation was necessarily to discredit; often the complainant saw this as being helpful. This variable is one which the coders were able to rate as strong evidence of discrediting, inconclusive evidence, or no evidence of discrediting. This judgment was made on the basis of how relevant the mentioned information was to the actual situation reported. The distribution of discrediting information was:

\begin{tabular}{lr} 
Drinking & 32 \\
Divorce & 26 \\
Immoral behavior & 11 \\
Public assistance & 5 \\
Police record & 5. \\
Mental illness or retardation & 4 \\
Child removed from home & 2 \\
Other & 2 \\
None & 14 \\
\hline Total & 101
\end{tabular}

No differences were found by relationship of complainant to the family. This indicates that it was no more important for non-relatives to discredit than for relatives. This is another indication of the universality of this trait in the complaint process.

The following vignettes illustrate the kinds of complaint content that were interpreted as evidence of discrediting information. 
Strong evidence of discrediting

A neighbor phoned to report that the mother of a six month old boy was not feeding him solid food. She further stated that he was fed nothing but milk from a bottle unless he was visiting a relative. The was because the mother did not take the trouble to feed him. The complainant stated that the mother was on welfare, and had often had many young people to her place for beer blasts.

The mention of the mother's receiving assistance and entertaining young people with beer, though part of the complainant's definition of the complaint situation, did not actually refer to the complaint situation itself. These characteristics of the mother did not necessarily affect her ability to care for her child, but are presented as if they helped to interpret her neglecting behavior.

$\underline{\text { Inconclusive evidence of discrediting }}$

A complaint was received reporting the situation of five children who were not being supervised. The children were said to be filthy and had been involved in stealing. The complainant added that the house was in ill repair.

In this case there did not appear to be any strong mention of information which did not describe the situation being reported, with the exception of the house being in ill repair. The evidence was there but was not clearly strong. This was therefore classified as inconclusive.

Because of the universal characteristic of the variable just discussed, that of complainants' tendency to discredit, the following questions were posed to examine the relationship of this variable to 
several other variables:

(1) Is the relationship of the complainant to the family associated with the type of discrediting information given?

(2) Is the seriousness of the situation associated with the tendency to discredit?

(3) Does a breakdown in or a lack of a child care arrangement have any relationship to the tendency to discredit?

(4) Is the length of time the situation has been known to exist as sociated with the tendency to discredit?

(5) Is the motivation of the complainant related to the tendency to discredit?

(6) Is there a relationship between having cared for this child and the tendency to discredit?

The questions are dealt with individually in the order they are presented above.

Taking into account the relationship of the complainant to the family, it was found that there were no differences among relatives and non-relatives and agencies with the following exceptions: relatives were most apt to mention public assistance, non-relatives were apt to mention police records, and agencies were apt to mention immoral behavior.

Looking at seriousness of the situation, it was found that although there was not a positive correlation between seriousness of 
the situation and the degree to which the complainant attempted to discredit, the neglect cases showed most evidence of discrediting, with only three out of twenty-two cases not showing this trend.

In regard to the third question posed, where there was no breakdown in a child care arrangement or lack of a child care arrangement and where it was rated as low seriousness, the same relationship held; there was a strong tendency to discredit (gamma = $-.83)$.

Looking at the variable concerning the time the complainant thought the situation had existed, there is a relationship with tendency to discredit, with the highest percentage occurring when there was some prior knowledge or a clearly substantiated knowledge based on a long history of the complaint situation. Table XVII shows this relationship.

TABLE XVII

TENDENCY TO DISCREDIT BY LENGTH OF TIME SITUATION HAD EXISTED FOR TOTAL SAMPLE

\begin{tabular}{lcccc}
\hline \hline \multirow{2}{*}{$\begin{array}{l}\text { Evidence of } \\
\text { Discrediting }\end{array}$} & $\begin{array}{c}\text { Time Situation Existed } \\
\text { Incident }\end{array}$ & $\begin{array}{c}\text { Some } \\
\text { Knowledge }\end{array}$ & $\begin{array}{c}\text { Long } \\
\text { History }\end{array}$ & Tota1 \\
\hline Strong & 8 & 31 & 18 & 57 \\
Inconclusive & 7 & 8 & 3 & 18 \\
\hline Total & 15 & 39 & 21 & 75 \\
\hline \hline
\end{tabular}

(unknown $=26 ; \gamma=-.44 ; \quad \bar{\chi}^{2}=5.57,2 \mathrm{df}, \mathrm{p}<.10$ ) 
In regard to question five, there is no statistically significant difference in whether or not the complainant is apt to discredit when his motivation is rated as "child motivation" or "mixed motivation." The complainant seems least likely to discredit when he was rated as "self motivation."

In regard to having provided care for the child, it was found that the same relationship holds; there is still a tendency to discredit. 


\section{CHAPTER IV}

\section{INTERPRETATION OF THE FINDINGS}

This chapter consists of three sections that interpret the findings in Chapter III. It discusses the formulation of a typology, further hypotheses generated by the study and a possible theory of the complaint process. The theory will concentrate on the commu:nity phase of the process.

\section{TYPOLOGY OF THE COMPLAINT PROCESS}

A basic consistency was found among the several findings reported in Chapter III. Briefly summarized they are as follows:

(1) Abuse cases were rated high serious. 2

(2) Neglect only cases were characterized by strong evidence of discrediting of the parents by complainant.

(3) For low serious cases, lack of a child care arrangement was associated with little or no evidence of discrediting information.

(4) Only among inadequate supervision cases, which tended to be mixed with neglect characteristics, was there an association with

${ }^{2}$ Statistical data summarized in Appendix G. 
strength of discrediting information.

Thus, the evidence converged on a typology of the complaint process in which each different complaint situation involved a different profile of the complaint process.

Type of

Situation:

Abuse

Neglect

Inadequate

Supervision
Essential Element for a Successful Complaint:

Seriousness

Discrediting the Parents

No Child Care

Arrangement

Figure 3. Essential elements of the complaint process associated with type of situation.

The characteristic profiles of complaint process for each type of complaint situation are described in further detail as follows:

$\underline{\text { Abuse }}$

(1) In the vast majority of the cases, abuse situations were rated as more serious than other situations. Part of the reason for this was the manner in which seriousness was defined for the purposes of this study.

(2) In abuse cases, the complainant was not any more or any less apt to discuss the situation with someone prior to making the complaint. 
(3) The evidence of discrediting information was not associated with seriousness of the situation in this category.

(4) The motivation of the complainant was always mixed or of genuine concern for the child. No ratings of purely self-interested motivation were reported for abuse cases.

(5) Abuse cases were not likely to involve inadequate supervision.

\section{$\underline{\text { Neglect }}$}

(1) Among the neglect cases two-thirds were rated as low seriousness.

(2) The complainant was most apt to discuss a situation with someone prior to making a complaint that was classified as neglect.

(3) There was always strong evidence of discrediting information regardless of the seriousness of the situation in neglect cases.

(4) Neglect cases were more apt to be reported by a non-relative or agency than by a relative.

(5) There was a greater percentage of self -motivated complaints in cases classified as neglect than in cases classified as inadequate supervision or abuse.

\section{Inadequate supervision}

(1) Inadequate supervision càses were rated as low' serious rather than high serious in a ratio of four to one.

(2) The persons who complained about this type of situation were 
less apt to discuss it with someone prior to making a complaint, than persons complaining about neglect or abuse situations.

(3) The evidence of discrediting information for cases of inadequate supervision was likely to be stronger as the seriousness of the situation increases.

(4) Seventy-six per cent of the cases reported in this category involved a breakdown in or lack of a child care arrangement.

The conclusion these profiles suggest is that for each kind of complaint situation a different process operates in leading to a successful complaint: for abuse it is the clear and present serious danger to the child, for neglect it is the communication of discrediting information that interprets the motivation and behavior of the parents of the child, and for inadequate supervision it is the clear and obvious breakdown or lack of a child care arrangement.

Further study is needed, of course, to determine if this is a stable typology of child care complaints or merely represents the data obtained in this study.

\section{FURTHER HYPOTHESES GENERATED BY THE STUDY}

A significant finding of this study is the high frequency of reported cases that involve a breakdown in or a lack of a child care arrangement. Forty-seven per cent of the sample was represented by this characteristic, with the following frequency of identified 
reasons for occurrences:

\begin{tabular}{lr} 
Breakdown in existing arrangement & $20 \%$ \\
Failure to make an arrangement & $55 \%$ \\
Inadequate arrangement & $25 \%$ \\
\hline Total & $100 \%$
\end{tabular}

Numerous reasons can be suggested for this occurrence. One could be a personality characteristic of the parent. Examples would include impulsive behavior patterns or disorganization which impedes the parent's ability to formalize a child care arrangement. Other reasons may include inadequate finances to hire a babysitter, poor judgment as to the suitability of a babysitter, or ignorance on the part of the family as to the necessity of a child care arrangement. Additional reasons for the instability of child care arrangements involve the lack of convenient resources and the difficulty of maintaining satisfactory arrangements.

The prevalence of the complainant's discrediting as a part of the complaint process has been discussed in Chapter III. Several possible reasons were suggested as to the function of this universal characteristic: discrediting information could be a means for the complainant to legitimize his complaint, discrediting information may reflect the complainant's value judgment of the family being reported, discrediting information may be used by the complainant to present himself to the agency as a person who is competent to judge the situation he reports. This behavior pattern on the part of the 
complainant needs to be further examined as it could be an important factor in his own motivation for assuming the responsibility for his role in the complaint process. This suggests the hypothesis that the complainant will not assume responsibility for making a protective service referral until he can support his interpretation of the complaint situation with discrediting information. Another possible explanation is a concept of the cumulative effect of the complaint situation on the complainant in which the situation becomes more serious to the complainant the longer he knows about it until, under the weight of the cumulative evidence, he feels compelled to report it. Investigation of the se possibilities would add light to the puzzling data regarding the time lag between the situation being observed and reported.

Protective services for children are based on the premise that someone in the community will report a situation that appears to jeopardize a child. However, the findings of this study indicate that several factors, including the seriousness of the situation, are not decisive in the complainant's reporting of a case. It is a well publicized fact that many cases of child abuse or severe neglect do not get reported until they are identified in mortality statistics. These findings raise the question of evaluating the effectiveness of the present system of detecting and reporting protective service cases.

Generalizing from the above information, one might 
hypothesize that the present system of identifying protective service cases is inadequate.

\section{THEORY OF THE COMPLAINT PROCESS}

The community phase of the complaint process needs to be examined more thoroughly, as it is the base upon which the present system of protective services rests. Based on the findings of this study, and drawing upon the findings of Young's study of child neglect and abuse (1964), certain speculations can be made which serve as a guide to understanding the role of the complainant, and which identify areas requiring further examination. Attention will be given to these questions. What can be said about the complainant? How does he come to assume this role? How does the family being complained about affect this process?

Although information was not obtained about the complainant's socio-economic status, educational background, race, age or occupation, there is still significant information that lends itself to the formulation of a profile of the complainant. Chapter III dealt with who the complainant is. It was found that forty-three were nonrelatives. Of these forty-three, 94 per cent observed the situation first hand, and in only four of the cases reported by non-relatives was the situation thought to be an isolated incident. These findings, taken together, suggest that the complainant lived within close 
geographical proximity to the child's family. Most complainants are neighbors.

What does the complainant do in the process of making the complaint? Some of the complainants in this study mentioned their attempts to help the family involved, either expressing their concern for the child or their disapproval of the situation. Many discussed the situation with other neighbors or relatives either as an attempt to interpret the behavior or to seek confirmation and support in their decision to report the situation.

Why does the complainant accept this responsibility?. Much has been written about the unwillingness of community residents to become involved in difficulties outside their immediate family. It seems relevant to mention several possibilities that may swing the pendulum of ambivalence in the direction of taking action. The complainant may feel a responsibility to make the report, either because of his concern for the safety of the child or possibly out of concern that the standards of society be upheld. He may be concerned that if the situation is allowed to continue, severe harm or death will occur. The consequences of allowing this to occur might be feelings of guilt for not taking action, or it might be concern about what other people would think if they knew he allowed this situation to exist and did not take action. Another possibility may be the cumulative effect of the complaint situation in which the complainant tolerates the situation 
until he can no. longer do so. This concept would account for length of time the complainant knew about the situation before reporting it, even in the most serious cases. Once the decision is made to report the situation, what does the complainant need to know in order to make a successful complaint?. The complainant needs to recognize what is harmful to a child physically and emotionally. He also needs to know where to call to make the complaint if he expects action to be taken on his report. Finally, he needs to be able to interpret the behavior he has observed, and be able to communicate what he has observed.

What is there about the family in the complaint situation that is useful in understanding the complaint process? Is there some aspect of the family itself that causes the complainant to make the report, or is it the complainant's interaction with the family that forces the reporting? These questions cannot be answered at this time, but further investigation and study seems imperative if we are to reach an understanding of the community phase in the protective complaint process. Therefore, a brief summary of Young's (1964) findings is included, with a suggestion for the implication of these findings for the complainant, who is attempting to alter behavior.

The neglecting parent profile reveals an immature and impulsive parent who is indifferent toward his children. These parents have few standards of behavior and cannot set limits for themselves or their children; they are passive in seeking friendships and do not enjoy other people's company. Public 
criticism is met with anger--not conformity.

The abusive parent profile describes the parent who gets perverse satisfaction from the act of punishing, which is divorced from either provocation or rationale. This profile indicates a rejection by the parent of the normal activities and interests in life. They refuse outside help; they assume little responsibility for their actions and have little if any feelings of guilt.

The consequences of the parental attitudes described in the profile have serious implications for the community, and more specifically the complainant. The parents fail to respond voluntarily to the prescribed standards of behavior of their community. It seems safe to assume they will not conform to the informal social pressures that normally operate, such as condemnation or ostracism. The complainants, who may have attempted to influence the family's behavior by reasoning or interfering with some form of social pressure, found they were unsuccessful. If there is merit to these speculations, it would seem the complainant saw the agency as a last resort so that the formal system of a social agency would bring pressures to bear on this family that could not be brought in any other way. The concept of last resort could also account for the time lag between observation and reporting that observation. Could this idea of attempting to influence the family through informal pressures account in part for the time lag in knowing about a situation and reporting it?

It might then be hypothesized that the necessary characteristics for a protective service complaint include: (1) a complaint situation 
that violates the community norms, (2) first hand observation or reliable second hand information of the situation by someone outside the nuclear family, (3) ability on the part of that someone to interpret the behavior he observes, (4) passage of time for interpreting the situation and/or deciding that action is required, (5) willingness to take the responsibility for some action, (6) confirmation or social support from others in the community for interpreting and/or reporting the situation, (7) contact with an agency to lodge the complaint, (8) ability to communicate the complaint situation in such a manner as to legitimize or make the situation being reported appear plausible. 


\section{CHAPTER V}

\section{IMPLICATIONS FOR POLICY AND PRACTICE}

This chapter discusses some implications of the study for the building of a system to facilitate reporting. It explores possible problems that hinder reporting and suggests areas for further study. Research in other areas can contribute to the theory of the complaint process and several such studies are mentioned.

If a complaint is to be successful, the initial observation of the situation must be accompanied by a definition that this situation does not conform to the normal standards of child rearing. An observer, then, must act upon his own criteria of child rearing or reach such a decision in consultation with others. Thus, public awareness of the standard of normal child care becomes essential for identification of a deviant situation. Education in child rearing practice can serve two purposes. It can help parents in caring for their own children and define normal standards as a measure of what is acceptable in the community.

Emotional neglect is perhaps the most difficult characteristic for the layman to identify (Murphy 1963). In this study there were no cases where emotional neglect was mentioned as the only or primary 
characteristic of a situation. It was mentioned eighteen times but never alone. In this area there is a special need for knowledge of the criteria for healthy emotional growth of children.

The cases described in this study are situations where a complaint was successfully lodged with an appropriate agency. They are unique in the fact that someone had contact with the family and was aware that there was a problem. The contact was usually a relative, neighbor, or person who had cared for the child. It has been suggested that neglecting and abusing families often live in relative isolation from normal contacts (Young, 1964, Wasserman 1967). Are these referred cases, then, exceptional in the population? If this is the case, our social policy should emphasize efforts that reach out to identify children in need of protective service rather than reacting primarily to those instances where there is concern on the part of some individual. Systematic observation of children by school, public health, and social agencies with clear responsibility for reporting would aid in the case-finding process (Boardman 1963).

The extension of mandatory reporting laws to cover additional groups such as child care workers or even all citizens would give sanction to those who are aware of deviant child care. The responsibility thus placed upon the observer would by law be channeled to an official agency that could act upon the report.

The fact that half of the complainants were reported to have 
indicated spontaneously that they had talked to someone else about the situation indicates that social confirmation of the observation and complaint decision may play an important role in the complaint process. Asch (1957) has shown the influence of a group upon the judgment of an individual. Considerable pressure to conform to the majority's judgment is exerted by the knowledge of what others have decided. There are clear implications for the complaint process in Asch's discussion.

There are circumstances when the welfare of the individual and the group requires that each should act according to his conviction. Indeed, a human community depends on its members to contribute of their thinking and feeling. When this source of mutual correction and enlightenment is weakened, the social process is disturbed at its foundations; both the individual and the group are damaged (p. 23).

Complainants in this study sought confirmation at the family and neighborhood levels. When they notified an agency it was a request for action by the agency. Could agencies offer a consultive service to the public?. If so, there should be public awareness of the availability of someone who could assist the observer in making a judgment while the decision to seek action is being considered. Such services might be offered through informal channels by day care neighbors (Collins, Emlen, and Watson 1967), health nurses, or community agents.

The study did not investigate the characteristics of the complainants other than their relationship to the family and their 
involvement in caring for the children. A more complete picture could be obtained in further research by investigating factors such as socio-economic status, education, and position in the informal neighborhood social system. Interviews with complainants would provide information for study in greater depth of the motivations for complaints. A comparison could be made through study of individuals who knew about an abuse or neglect situation and did not complain. Such information might be obtained by tracing the contacts of a family in the period before the situation comes to public attention. An example of information available is contained in a newspaper report of the murder of a child and the events that preceded it.

About a week later, George Carlings, a student at Portland State College who lived next door to the Bryants, heard a strange thumping coming from the Bryants room. "It sounded as if something was hitting the wall, "he would say later. He also heard the sound of crying. The next day Ronnie was seen with another black eye and again, bruises all over his body.

But still another chance to stop Ronnie's murder went by when Carlings failed to report the matter to police. "I told myself not to be a meddler, " he testified later. (Davis 1968)

The unwillingness of the public to intervene in or report a crisis situation has had much attention in the public press. A recent article in Psychology Today (Darley 1968) describes the steps that must be taken by an individual before intervention. (1) He must notice the situation (observation). (2) He must interpret the event as an emergency (define deviance). (3) He must decide that he has 
personal responsibility for intervention. Experimental evidence indicated that the presence of others inhibited the observation of an emergency and the definition of the situation as a crisis. Individuals who observed an emergency sought confirmation through the behavior of others. If others remained indifferent the observer tended to remain indifferent, at least in his actions. The knowledge that others were aware of the crisis and were not responding, tended to inhibit the intervention of the subjects in these experimental situations. From the study of other types of crisis situations we might gain insight into the apparent apathy or the reluctance to complain indicated in neglect and abuse cases that go unreported for long periods.

A study of decisive incidents that become the "last straw" in the process of seeking hospitalization of schizophrenic patients may have implications for the reporting of child abuse and neglect (Smith, Pumphrey, and Hall 1963). The family and community tolerated the patient even though they understood that he was mentally ill. The two most prevalent types of decisive incidents concerned fear of the patient and social exposure. Situations that indicate these types of motivation would correspond to those classified mixed and self concern in this study. More than half of the complainants from the private sector showed some degree of concern for self. The personal. involvement of the complainants through fear of harm or discomfort to themselves, and the possibility of community awareness that would 
reflect on family prestige may be factors in the decision to report the situation.

The person who observes child abuse that is not severe and life threatening may face a psychological dilemma. Gil and Noble (1967) in a study of public knowledge, attitudes, and opinions about neglect and abuse found that 22.3 per cent of those interviewed thought that they could injure a child and, in fact, 2.5 per cent admitted to having done so in the past. Boardman (1962) cites the case of two policewomen in a juvenile division, who decided not to file petitions on behalf of two abused children and said, in almost identical words, "I can understand the problems of the mother. I have had to support and rear my children by myself" (p. 47). This tendency to identify with the parents hinders the rational assessment of the problem and can impede the protective response. The part that this phenomenon plays in the complaint process could be investigated in further research. It seems that professional consultation might play a part in helping the observer to make a realistic judgment of the situation.

The laws that apply to negligent or abusive families contain a double message. The juvenile court acts in behalf of the child for his protection. The criminal court acts punitively toward the abusive parent. Although the placement of the child is not intended as punishment for the parents it is often regarded as punitive. This confusion in society's attitude toward a family may well be reflected in 
confusion on the part of the observer who must decide whether or not to report the situation. The adoption of a consistent legal policy of concern for the entire family would not only simplify the problems of treatment but would resolve the dilemma of the complainant who must consider what the response to his report will be.

There are differences in the initial services offered by the three agencies in this study. The Women's Protective Division accepts anonymous complaints, investigates, and can take immediate action in an emergency. Welfare accepts anonymous complaints but does not take emergency action such as removing the child without prior court approval. The Juvenile Court does not accept anonymous complaints and does not act to intervene without judicial action.

The complainant who desires confidentiality or who is reporting a crisis situation may make more than one call to find the appropriate agency for a specific complaint. Cooperation between agencies in referring complainants to the appropriate agency assists the complainant in the process of reporting. Nevertheless, the complainant's task may be made more difficult by the necessity of making more than one call.

Young (1964) suggests that a special police division working in close collaboration with a child welfare agency is the most practical solution to controversy about what type of agency should take the initial responsibility in neglect and abuse cases. Complaints could be 
made to either agency with police taking responsibility for investigation and welfare concerning itself with long range planning for and care of children. Although there is cooperation among the agencies in this study there is a duplication of the investigative function that may make it difficult for complainants to decide which agency to contact.

Another difficulty for the complainant is presented in the multiple functions of the protective agencies. The Police Bureau is primarily identified with law enforcement, the Welfare Commission with public assistance, and the Juvenile Court with delinquency. No subdivision of these agencies deals exclusively with protective services. It seems reasonable to suggest that the public might have difficulty knowing whom to contact for protection of children.

This project has examined the community's early response to the mistreatment of children. The findings outline the complex elements that comprise a successful complaint. If, indeed, we have a responsibility for the protection of children, can we leave the initiation of the process to chance discovery by an interested bystander, or must we extend our concern through examination and facilitation of the process? 


\section{A SELECTED BIBLIOGRAPHY}

Anderson, Theodore R., and Morris Zelditch, Jr., A Basic Course in Statistics with Sociological Application, 2nd ed., New York, Holt, Rinehart and Winston, 1968.

Asch, Soloman E., "An Experimental Investigation of Group Influence," Symposium of Preventive and Social Psychiatry, Walter Reed Army Institute of Research, United States Government Printing Office, 1957.

Boardman, Helen E., "A Project to Rescue Children from Inflicted Injuries," Social Work, VII, (January, 1962), 43-51.

, "Who Insures the Child's Right to Health?" The Neglected Battered-Child Syndrome, New York, Child Welfare League of America, Inc., 1963, 5-12.

Boehm, Bernice, "The Community and the Social Agency Define Neglect, " Child Welfare, (November, 1964), 453-464.

Campbell, D. T., and D. W. Fiske, "Convergent and Discriminant Validation by the Multitrait - Multimethod Matrix, " Psychological Bulletin, LVI, (1959), 81-105.

Class, Norris E., "Neglect, Social Deviance, Community Action," NPPA Journal, VI, (January, 1960), 17-23.

Collins, Alice H., Arthur C. Emlen, and Eunice Watson, "The Day Care Neighborhood Study: An Interventive Experiment," mimeograph, 1967.

Cronbach, Lee J., and Paul E. Meehl, "Construct Validity in Psychological Tests," Psychological Bulletin, LII, (1955), $281-302$.

Darley, John M., and Latane Bibb, "When Will People Help in a Crisis?" Psychology Today, II, (December, 1968), 54-71. 
Davis, Dave, "Tragedy Compounded by Public Apathy," The Oregon Journal, (June 12, 1968).

De Francis, Vincent, Protective Services and Community Expectations, Denver, American Humane Society, 1961.

Elmer, Elizabeth, "Abused Children Seen in Hospitals," Social Work, V, (October, 1960), 98-102.

, "Hazards in Determining Child Abuse," Child Welfare, XLV, (January, 1966), 28-33.

Emlen, Arthur C., Field Study of the Neighborhood Family Day Care System: Second Progress Report, mimeograph, (July 1, 1968).

Fellin, Phillip, and Eugene Litwak, "The Neighborhood in Urban American Society," Social Work, XIII, (July, 1968), 72-80.

Garfinkel, Harold, "Conditions of Successful Degradation Ceremonies, " The American Journal of Sociology, LXI, (March, 1956), $420-424$.

Gil, David G., and John H. Noble, "Public Knowledge, Attitudes and Opinions about Physical Child Abuse in the United States," Papers in Social Welfare, Brandeis University, September, 1967.

Goodman, Leo A., and William H. Kruskal, "Measures of Association for Cross Classifications," Journal of American Statistical Association, XLIX, (December, 1954), 732-764.

Guilford, J. P., Fundamental Statistics in Psychology and Education, New York, McGraw, 1956.

Jeter, Helen R., Child Problems and Services in Child Welfare Programs, United States Department of Health, Education and Welfare, Childrens Bureau, 1963.

Kempe, C., et al. , "The Battered Child Syndrome," Journal of the American Medical Association, CXXCI, (July 7, 1962), 17-24.

Landy, D. "Problems of the Person Seeking Help in Our Culture," Social Welfare Forum, Columbia University Press, New York, $1960,127-145$. 
Lazarsfeld, Paul F., "Evidence and Inference in Social Research," Readings in the Philosophy of the Social Sciences, Ed. by May Brodeck, New York, Macmillan Co., 1968, 608-634.

, and Morris Rosenberg (eds.), The Language of Social Research, New York, The Free Press of Glencoe, 1955.

Murphy, Lois B. , Problems in Recognizing Emotional Disturbances in Children, New York, Child Welfare League of America, New York, 1963.

Patchen, Martin, Some Questionnaire Measures of Employee Motivation and Morale: A Report on Their Reliability and Validity, Institute for Social Research Center Monograph No. 41, Ann Arbor, Michigan, 1965.

Phillips, Bernard S., Social Research: Strategy and Tactics, New York, Macmillan Co., 1966.

Scott, William A., and Michael Wertheimer, Introduction to Psychological Research, New York, John Wiley and Sons, 1964.

Senders, Virginia L., Measurement and Statistics, New York, Oxford University Press, 1958.

Siegel, Sidney, Nonparametric Statistics for the Behavioral Sciences, New York, McGraw Hill Book Co., 1956.

Smith, Kathleen, Muriel Pumphrey, and Julian Hall, "The Last Straw: The Decisive Incident Resulting in the Request for Hos pitalization in 100 Schizophrenic Patients, " The American Journal of Psychiatry, CXX, (September, 1963), 228-233.

Streshinsky, Naomi, Andrew Billingsley, and Vonnie Gurgin, "A Study of Social Work Practice in Protective Services: It's Not What You Know, It's Where You Work, " Child Welfare, XLV: 8, (October, 1966), 444-450.

Tri-County Community Council, Directory of Community Services, Portland, Oregon, 1965.

Wasserman, Sidney, "The Abused Parent of the Abused Child," Children, XIV:5, (September-October, 1967), 175-179. 
Young, Leontine, Wednesday's Children: A Study of Child Neglect and Abuse, New York, McGraw Hill, 1964.

Zalba, Serapio R., "The Abused Child: I.A Survey of the Problem," Social Work, XI:4, (October, 1966), 3-16. 
$=$ 
Portland State College

School of Social Work
July 24, 1968

William Carey, et al. Dr. Emlen, Project Advisor

\section{QUESTIONNAIRE ABOUT THE COMPLAINT PROCESS IN PROTECTIVE SERVICES FOR CHILDREN}

With this questionnaire we are interested in learning about how Protective Service complaints are made. We are interested in the network of persons who may be involved either in the complaint situation or in the complaint process.

Our aim is to develop a classification and description of complaint processes that could suggest ways of intervening more easily in protective service situations to prevent child neglect.

The questionnaire is designed for use by community agencies at the point of intake for any complaint or contact made in which concern is expressed about the care of a child.

The complainant can be any person in the community or any agency representative making this contact with this agency. If there is more than one complaint, try to complete a separate questionnaire for each.

The questionnaire is divided into four sections:

I. The content of the complaint: Who complained about what to which agency?

II. Observation of the complaint situation: How did the complainant become involved?

III. Community involvement in the complaint process: Whom did the complainant talk to about the complaint situation and who became involved (directly or indirectly) in making the complaint.

IV. Disposition and additional information: What was the agency's response to the complaint?

Thank you for your help in this study. Please feel free to make any suggestions about additional information you think is relevant. 
Date complaint made to agency

Name of agency receiving complaint:

I. THE CONTENT OF THE COMPLAINT

Name of the complainant (What person or agency made this contact with your agency?):

Description of the situation complained about.

Name of worker receiving complaint:

What did the complainant state as the reason for calling at this time?

Did the complainant suggest or imply what specific action should be taken?

Yes___ No___ If yes, describe:

(Identifying information to be removed after case is checked for inter-agency duplication)

Family Name

Name(s) of child (children) Age
With whom was child living when complaint situation occurred?

$\overline{\text { First Name Last Name }}$ 


\section{OBSERVATION OF THE COMPLAINT SITUATION}

Describe how the complainant happened to see or know about the situation. How well did the complainant know the family and in what way? Please be as specific as you can about any direct or indirect relationship between the complainant and the family.

To the complainant's knowledge, how long had the situation existed?

Was the complainant taking care of the child(ren) during the period of time of the complaint situation?

Yes No Comment:

If yes, was it for pay?

Had the complainant ever taken care of the child(ren) in the past?

Yes No Comment:

If yes, was it for pay?

Was a breakdown in, or a lack of, a child care arrangement (babysitting) involved in the complaint situation in any way?

Yes No

If yes, who was supposed to be providing the child care and how did the arrangement break down? 


\section{THE COMMUNITY-INVOLVEMENT PHASE OF THE} COMPLAINT PROCESS

Describe in as much detail as you can the complainant's community contacts leading up to contact with this agency. Before making this agency contact, whom did the complainant feel a need to consult or confide in, and for what apparent purpose? (Include such contacts as neighbors, relatives, and agencies, etc.)

If possible would you please go back and number the order of the sequence in which these people became involved.

\section{DISPOSITION AND ADDITIONAL INF ORMATION}

What was the agency's initial response to the complaint?

Is there any other information that you feel is pertinent? If so, please include here or attach additional page. 
APPENDIX B

CODING INSTRUCTIONS 
I. The content of the complaint

(A) Source of the complaint

(a) Agency personnel: any complainant who represents any organization; e.g. , a government agency, church, school, etc.

(b) Private individual: anyone who feels a personal responsibility to make a complaint

Individual acting in his professional capacity: a person making a complaint because he feels a professional responsibility to do so; e.g., doctor in private practice, parking lot attendant, babysitter, etc.

(B) Situation complained about (check all that apply)

(1) Neglect

(a) Inadequate physical (bodily) care: severe diaper rash, not clean, etc.

(b) Inadequate food: not enough food or inappropriate food

(c) Inadequate supervision: children left alone, roaming unattended, or left in the care of an incompetent person

(d) Inadequate medical care: failure to obtain medical care or follow through with medical treatment

(e) Exposure to immoral environment: excessive drinking, bad language, or lewd and lascivious co-habitation

(f) Unsanitary and unsafe housing conditions: filthy or badly cluttered

(g) Inadequate or unsafe housing: overcrowded, unheated, structurally unsound, lack of plumbing

(h) Emotional neglect: child ignored, child not provided with love or affection, parent does not care for child

(i) Failure to send to school

(j) Inadequate clothing: lack of clothing, poor condition of clothing, or inappropriate clothing

(k) Other neglect

(2) Inadequate parenting ability

(a) Mental illness: parent behaves in a bizarre manner

(b) Physical illness or handicap: parent deaf, mute, blind, bedfast

(c) Emotional instability: parent impilsive, unpredictable, withdrawn, easily enraged, overly fearful or protective 
(d) Mental retardation

(e) Other

(3), Abuse

(a) Battering: hitting with hand, hitting with object, throwing against a wall, burning, or kicking

(b) Sexual abuse: incest, rape, sexual molestation, seductive behavior

(c) Emotional abuse: harassment, berating the child, physical restriction

(d) Other

(4) Abandonment

(a) At home unattended

(b) With babysitter: parents failed to return

(c) In public place unattended: a park, service station, on the street, etc.

(d) Other

(5) Exploitation*

(a) Parents pimping for child

(b) Parents exploiting child through work

(c) Parents inducing child to steal

(d) Other

(C) Seriousness of the situation (in terms of harm to child) When several problem situations are described, code according to the most serious item mentioned. $* *$

(a) Marginal: a situation that is not necessarily harmful but could be detrimental; i. e., an older child (9-12 years old) left alone for several hours, a dirty child, an adolescent girl entertaining boys, an existing babysitting arrangement fails

(b) Moderate: children on the street at late hours, exces sive drinking in the home, unkempt or unsanitary housing, illicit sexual relations in the home, inadequate diet--no immediate danger, unfit babysitter, older child left alone for long periods --all day or all night, inadequate supervision, or a series of marginal complaints

(c) Serious: small children left alone, failure to educate, failure to provide adequate medical care, overly punitive (beating, kicking, etc.), young child left alone (to 6 years), child abandoned in a public place, or indecent

*Item omitted during coding **item added during coding 
seductive exposure

(d) Very serious: deforming or maiming a child, harming a child in a way that threateris the child's life, scalding, burning, breaking bones, sexual abuse (incest, rape, molestation), severe malnutrition

(D) Discrediting information that legitimizes complaint

(a) Divorced or in process of getting a divorce

(b) On public assistance

(c) Police record

(d) Children removed in the past

(e) Family in debt

(f) Minority race

(g) Mental illness

(h) Immoral behavior on part of parents

(i) Unemployment

(j) Excessive drinking

(k) Parent unpleasant toward complainant

(1) Mental retardation

(m) Other

(n) None $^{* * *}$

(E) Evidence of complainant's discrediting of parents Do not look for the severity of the information given to discredit, but how obvious it is that the information has been given in order to discredit

(a) Strong: the discrediting information is unrelated to the complaint; e.g., when the complaint is about excess punishment of children and the complainant states that the father is unemployed, on welfare, etc.

(b) Inconclusive: the discrediting information is related to the complaint; e.g., when the complaint is regarding an inadequate diet and the complainant mentions that the father is unemployed, on welfare, etc.

(c) No evidence: no discrediting information given

(F) Motivation for the complaint

(a) Genuine concern for child: the complainant does not appear to be motivated by self-interest and/or he expresses concern for the safety or well-being of the child 
(b) Mixed-concern for child and self-concern: the complainant expresses concern for himself or his property as well as concern about possible harm to the child

(c) Self-concern: the complainant expressed primary concern for himself or his property; e. g., a garden is being ruined, a sitter is owed money, excessive noise is being made, property is being destroyed, the complainant wants custody of the children

(d) Call made at the request of someone else

(e) Vindictiveness toward parent*

(f) Vindictiveness toward child*

(g) Other*

(h) Unknown

(G) Action suggested or implied by complainant

(1) Appropriateness of complainant's suggested action to services provided by the agency: This item refers to the appropriateness of a suggested action to services provided by the agency--not to the appropriateness of the suggested action to the role of any individual employee within the agency.

(a) Appropriate: a suggestion to the police that they investigate, a suggestion to a welfare caseworker that a mother needs help in learning to take better physical care of her child, a suggestion to the juvenile court that a child be removed, etc.

(b) Inappropriate: a suggestion to the police department that a child's legal custody be changed, a suggestion to the juvenile court that a night visit be made, etc.

(c) Questionable: anything that doesn't fit into the above categories

(2) Complainant's recommended or implied action

(a) No sugge stion

(b) Investigation

(c) Counsel parents

(d) Coerce parents into adequately caring for children

(e) Terminate parental right

(f) Prosecute parents

(g) Place the children in the home of the complainant, a friend or relative

(h) Remove children 
(i) Other

(j) Place children in shelter or foster care**

(H) Age

If a child is described as being a year old, he should be placed in the 13 month through 2 year old category. If es timated ages are given, such as if the child is described as 2 or 3 years of age, use the upper age bracket.
(a) 0-12 months
(b) $\overline{13 \text { month } s-2}$ years
(c) 3-5 years
(d) $6-11$ years
(e) 12 years and older
(f) Unknown

(I) The person the child was living with at the time of the complaint situation: This refers to the child's place of permanent residence. The child is considered a resident in his parental home if he is living with either parent. $* *$
(a) Parental home
(b) With a relative
(c) With a babysitter
(d) Foster home
(e) Other
(f) Unknown

II. Observation of the complaint situation

(A-1) How the complainant happened to see or know about the situation
(a) Direct observation: this includes any observation
(b) Second-hand information
(c) Information given to complainant by victim
(d) Unable to determine

(A-2) Sex of complainant
(a) Male
(b) $\overline{\text { Female }}$
(c) Sex unknown
(d) Inapplicable (agency, etc.)

***Item added during coding 
(A-3) Relationship between complainant and family

Relative
(a) Self-referral by child
(b) Mother
(c) Father
(d) Step-mother
(e) Step-father
(f) Maternal grandparent
(g) Paternal grandparent
(h) Other relative

Non-relative

(a) Neighbor

(b) $\overline{\text { Presumed neighbor }}$

(c) Stranger*

(d) Acquaintance

(e) Friend

(f) Physician

(g) Housekeeper **

(h) Babysitter

(i) Parent of a friend of the child

(j) Anonymous

(k) Other

(1) Landlord or apartment manager***

Agency personnel

(a) Public Health personnel

(b) School personnel

(c) Juvenile court personnel

(d) Public welfare personnel

(e) Church representatives

(f) Other

(g) Law enforcement agency****

Unknown

(B) The length of time the situation had existed to the complainant's knowledge

(a) An isolated event

(b) Some prior knowledge: includes any situation reported that is not based on a single epi sode or event

(c) Clearly substantiated knowledge based on a long history of the complaint situation: those situations

*Item omitted during coding

***Item added during coding 
that had existed more than three months to the complainant's knowledge

(d) Unknown

(C-1) Was the complainant caring for the child(ren) during the period of time of the complaint situation?
(a) Yes
(b) No
(c) $\overline{\text { Unknown }}$

(C-2) If yes, was it for pay?

(a) Yes

(b) No

(c) Unknown: Check as unknown if preceding question is answered unknown.

(d) Not-applicable:** Show as not applicable all items checked no in preceding question.

(D-1) Had the complainant ever taken care of the child(ren) in the past?
(a) Yes
(b) No
(c) Unknown

(D-2) If yes, was it for pay?

(a) Yes

(b) No

(c) Unknown: Show as unknown if the preceding question is answered unknown.

(d) Not-applicable:**Show as not applicable all items checked no in preceding question.

(E-1) Was a breakdown in, or a lack of, a child care arrangement involved in the complaint situation in any way?
(a) Yes
(b) No
(c) Unknown

(E-2) If yes, relationship of child care arrangement to the complaint situation

***item added during coding 
(a) Breakdown in existing a rrangement: e.g., a babysitter leaves the place where she is caring for children, thereby leaving the children unattended

(b) Previous babysitting arrangement failed; no arrangements made for the present: e. g., sitter sick, injured, on vacation, etc, , with no arrangement made by the mother for a replacement

(c) Failure to make a child care arrangement: e. g., no child care arrangement has been made for the present and there is no mention of a previous child care arrangement having been made in the past

(d) Inadequate child care arrangements made: e. g. , sitter too young or physically handicapped to care for the child or a neighbor asked to look in on a very young child in a nearby home periodically

(e) Not applicable***

(F-1) Person who was supposed to be providing child care (check all that apply)
(a) Mother
(b) Father
(c) Sibling
(d) Grandparent
(e) Other relative
(f) Group care center
(g) Paid sitter
(h) Neighbor
(i) Friend
(j) Other
(k) No one
(1) Unknown
(m) Not applicable***

(F-2) The way the child care arrangement broke down (check all that apply)
(a) Parent failed to arrive home at designated time
(b) Child not taken to regular sitter by parent
(c) Sitter refused to continue with arrangement due to lack of pay
(d) $\overline{\text { Sitter ill }}$
(e) Sitter injured

*** Item added during coding 
(f) Sitter deserted children

(g) Sitter not supervising children adequately

(h) Unknown

(i.) Other

(j) Not applicable***

III. Did the complainant discuss the situation with anyone before making the complaint?
(a) Yes
(b) No
(c) Unknown: this should be checked unless the questionnaire specifically states the complainant did or did not discuss the situation with another person prior to making the complaint

IV. The agency's initial response to the complaint (check all that apply)
(a) Not accepted for services
(b) Investigation initiated
(c) Children placed in foster care, shelter care or detention
(d) Consultation with professional person outside the agency 
APPENDIX C

INDIVIDUAL CODE SHEET 


\section{INDIVIDUAL CODE SHEET}

I. A. $\quad / 1 / 1$

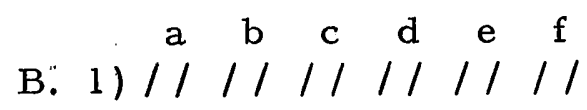

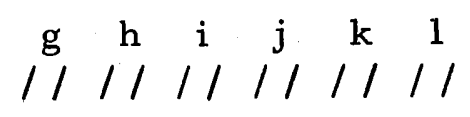

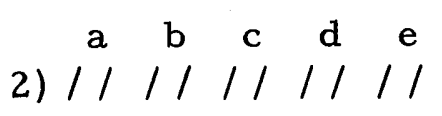

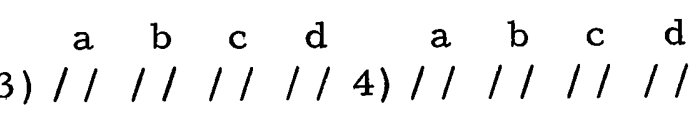

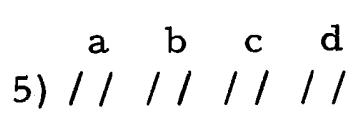

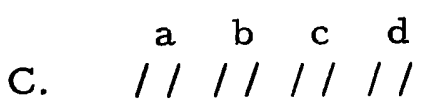

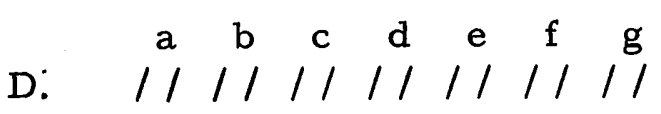

$\begin{array}{cccccc}\mathrm{h} & \mathrm{i} & \mathrm{j} & \mathrm{k} & \mathrm{i} & \mathrm{m} \\ / / & / / & / / & / / & / / & /\end{array}$

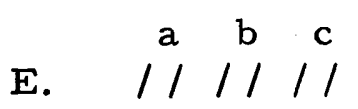

$\begin{array}{ccccccccc} & \mathrm{a} & \mathrm{b} & \mathrm{c} & \mathrm{d} & \mathrm{e} & \mathrm{f} & \mathrm{g} & \mathrm{b} \\ \text { F. } & / / & / / & / / & / / & / / & / / & / / & /\end{array}$

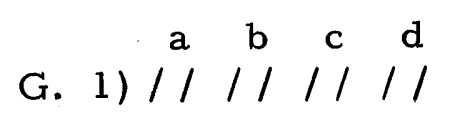

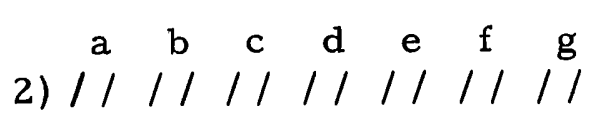

$\begin{array}{cccc}\mathrm{h} & \mathrm{i} & \mathrm{j} & \mathrm{k} \\ / / & / / & / / & /\end{array}$

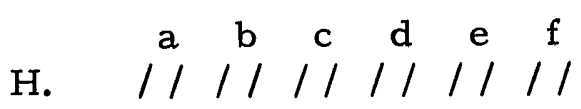

a b c d e f

I. $1 / 1 / 1 / 1 / 1 / 1$
3) Relative $\stackrel{a}{ } / / / / /$

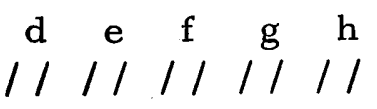

Non-relative / / / /

c $d$ e $\mathrm{f}$ g $\mathrm{h}$

111111111111

$\begin{array}{lll}\mathrm{i} & \mathrm{j} & \mathrm{k} \\ / / & / / & /\end{array}$

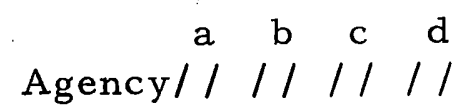

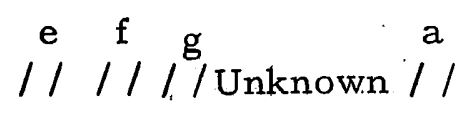

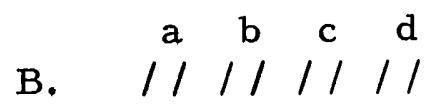

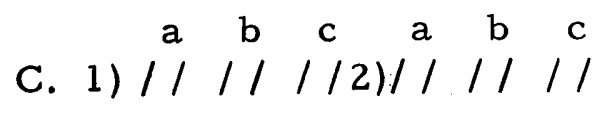

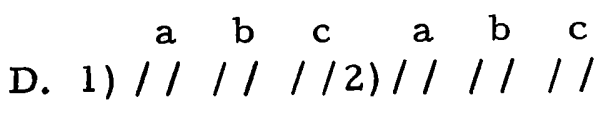

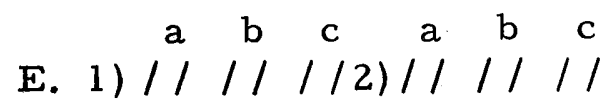

$\begin{array}{ll}\mathrm{d} & \mathrm{e} \\ / & /\end{array}$

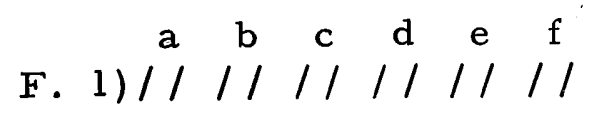

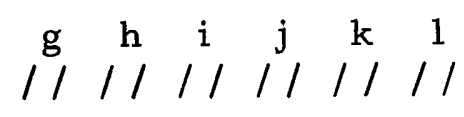

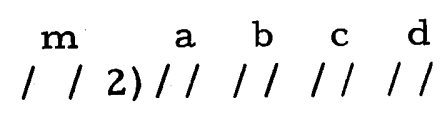

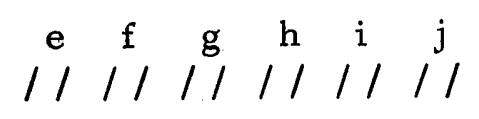

II: A." 1$)=\left[\begin{array}{ccccccccccc}a & b & c & d & a & b & c & d & a & b & c\end{array}\right.$ 
APPENDIX D

OMISSION AND CONSOLIDATION OF CATEGORIES FOR ANALYSIS 
I. The content of the complaint

A. Source of the compaint

a. Agency personnel

b. Private individual and/or individual acting in professional capacity

B. Situation complained about

1. Neglect

a. Inadequate physical (bodily) care

b. Inadequate food

c. Inadequate supervision

d. Inadequate medical care

$(\mathrm{I}-\mathrm{B}-1-\mathrm{a})$

e. Exposure to immoral environment

f. Unsanitary and unsafe living conditions

g. Inadequate and unsafe housing

$(I-B-1-f)$

h. Emotional neglect

i. Failure to send to school

j. Inadequate clothing

k. Other

(Omitted)

2. Inadequate parenting ability due to:
a. Mental illness
b. Physical illness: or handicap
c. Emotional instability
d. Mental retardation
e. Other

3. Abuse
a. Battering
b. Sexual abuse
c. Emotional abuse 
d. Other

4. Abandonment
a. At home unat- tended
b. With babysitter, parents failed to return
c. In public place unattended

d. Other

C. Seriousness of situation
a. Marginal
b. Moderate
c. Serious
d. Very Serious

D. Discrediting information that legitimizes complaint
a. Divorced or in process of getting divorce

b. On public assistance

c. Police record

d. Children removed in the past

e. Family in debt

f. Minority race

g. Mental illness

h. Immoral behavior on part of parents

i. Unemployment

j. Excessive drinking

8

k. Parent unpleasant toward complainant

1. Mental retardation

m. Other

n. None 
Category

Code

2

3

1

2

3

4

5

1

2

3

1

2

3

4
Item Omitted Column

or Combined Number

E. Evidence of complainant's discrediting of parents
a. Strong
b. Inconclusive
c. No evidence

F. Motivation for complaint

a. Genuine concern for child

b. Mixed concern for child and self

concern

c. Self concern

d. Call made at the request of someone else

e. Unknown

G. Action suggested or implied by complainant

1. Appropriateness of complainant's suggested action to services provided by the agency
a. Appropriate
b. Inappropriate
c. Questionable

2. Complainant's recommended or implied action

a. No suggestion

b. Investigation

c. Counsel parents

d. Coerce parents into adequately caring for children

e. Terminate parental rights

f. Prosecute parents

(Omitted) 
Category

Code

5

6

7

8

1

2

3

4

5

g. Place the children in the home of the complainant, a friend or relative

h. Remove children

i. Other

j. Place children in shelter or foster care

H. Age

a. 0-12 months

b. 13 month -2 years

c. 3-5 years

d. 6-11 years

e. 12 years or older

f. Unknown

I. The person with whom the child was living at the time of the complaint situation

(Omitted)

a. Parental home

b. With a relative

c. With a babysitter

d. Foster home

e. Other

f. Unknown

II. Observation of the complaint situation

A. 1. How the complainant happened to see or know about the situation

1

2

3

4

a. Direct observation

b. Second-hand information

c. Information given to complainant by victim

d. Unable to determine 
2. Sex of complainant

1

a. Male

b. Female

c. Sex unknown

d. Inapplicable (agency, etc.)

3. Relationship between complainant and family
a. Relative

b. Non-relative

c. Agency personnel

d. Unknown

B. The length of time the situation had existed to the complainant's knowledge
a. An isolated event
b. Some prior knowledge
c. Clearly substantiated knowledge based on a long history of the complaint situation

d. Unknown
(Subcategories omitted)

C. 1. Was the complainant caring for the children during the period of time of the complaint situation?

a. Yes

b. No

c. Unknown

2. If yes, was it for pay?

a. Yes

b. No

c. Unknown

d. Not applicable 
Category

Code

Item Omitted Column

or Combined Number

D. 1. Had the complainant

ever taken care of the

child(ren) in the past?

a. Yes

b. No

c, Unknown

2. If yes, was it for pay?

a. Yes

b. No

c. Unknown

d. Not applicable

E. 1. Was a breakdown in, or

a lack of, a child care arrangement involved in the complaint situation in any way?

1

a. Yes

b. No

c. Unknown

2. If yes, relationship of child care arrangement to the complaint situation

a. Breakdown in existing arrangement

b. Previous babysitting arrangement failed; no arrangement made for the present

c. Failure to make a child care arrangement

4

d. Inadequate child care arrangements made

0

e. Not applicable

F. 1. Person who was supposed to be providing child care 
Category

Code

3

4

0

1

2

3

4 b. Father

c. Sibling

d. Grandparent

e. Other relative

f. Group care center

NON-RELATIVE

g. Paid sitter

h. Neighbor

i. Friend

j. Other

k. No one

1. Unknown

m. Not applicable

2. The way the child care arrangement broke down PARENT FAILURE

a. Parent failed to arrive home at designated hour

b. Child not taken to regular sitter by parent

SITTER FAILURE

C. Sitter refused to continue with arrangement

d. Sitter ill

e. Sitter injured

f. Sitter deserted children

g. Sitter not supervising adequately

h. Unknown

i. Other

j. Not applicable
Item Omitted Column

or Combined Number

(II -F - l -e)

(II $-\mathrm{F}-1-\mathrm{e}$ )

(II $-F-1-e)$

(Omitted)

(Omitted)

(Omitted)

(Omitted)

$($ II $-F-2-i)$

III. Did the complainant discuss the situation with anyone before making the complaint?

a. Yes 
Category

Code

2

b. No

c. Unknown
Item Omitted Column

or Combined Number

IV. The agency's initial response to the complaint

a. Accepted for services

b. Not accepted for services

3

c. Investigation initiated

d. Children placed in foster care, shelter care, or detention

e. Consultation with professional person out side the agency

Added categories:

1-7 Number of situations reported by complainant

Type of situation reported

Inadequate supervision, no abuse Abuse, no inadequate supervision Inadequate supervision and abuse Neglect, no abuse or inadequate supervision 
APPENDIX E

\section{DISTRIBUTIONS}


$\underline{\text { Referral source }}$

Agency 31

Private $\frac{70}{101}$

WPD 56

Shelter Care 16

Family Service 3

Children's Department 18

Juvenile Court

$\frac{8}{101}$

Seriousness of situation

Marginal 13

Moderate 43

Serious $\quad 36$

Very Serious $\frac{9}{1 \theta 1}$

Discrediting information

Divorced 26

Public Assistance 5

Police Record 5

Child Removed 2

Mental Illness 4

Immoral Behavior 11

Drinking $\quad 32$

Parent Unpleasant 0

Other 2

None 14

$\frac{14}{101}$

Evidence of discrediting information

Strong

Inconclusive or No

$\frac{32}{101}$ 
Motivation

Child Concern 56

Mixed Concern . 28

Self Concern $\quad 12$

Unknown

Appropriateness of recommendations

Appropriate

Inappropriate
44

$\frac{57}{101}$

Recommended actions

No Suggestion $\quad 45$

Investigation 25

Counsel Parents 2

Coerce Parents 3

Place Children in a Known Home 4

Remove Children 4

Other 5

None 13

$\overline{101}$

How complainant knew about situation

Direct Observation $\quad 64$

Second-Hand Observation 19

Unknown

$\frac{18}{101}$

Time complainant knew about the situation prior to complaining

Isolated Event

Some Prior Knowledge 49

Clearly a Long History 21

Unknown 
Complainant caring for child at time of complaint

Yes

No

89

Unknown

Complainant cared for child in the past

Yes

No

Unknown

Breakdown in or lack of a child care arrangement at the time of the complaint

Yes

No

Unknown

$\underline{\text { Reason child care arrangement failed }}$

Existing Arrangement failed

Previous Arrangement failed

No New Arrangement

Failure to Make an Arrangement

Inadequate Arrangement

Who was supposed to be caring for the child at the time the arrangement failed?

Mother

Other Relative

Non-Relative

12

Unknown

$\frac{0}{47}$

Did complainant discuss situation prior to making complaint?

Yes

No or Unknown 
Response of the agency to the complaint

Accepted for Service 3

Not Accepted for Service 8

Investigation $\quad 72$

Placed Child $\frac{18}{101}$

Number of characteristics reported in

a single complaint

1 Characteristic 44

2. Characteristics $\quad 27$

3 Characteristics 20

4 Characteristics 8

5 Characteristics 1

6 Characteristics 0

7 Characteristics $\frac{1}{101}$

Types of situations

Abuse $\quad 32$

Neglect $\quad 22$

Inadequate Supervision $\frac{47}{101}$

Inadequate supervision involved in the complaint

Yes 49

No .

$\overline{101}$

Abuse involved in the complaint

Yes $\quad 32$

No $\frac{69}{101}$

Immoral behavior involved in the complaint

Yes 24

No $\frac{77}{101}$ 
Inadequate medical care involved in the complaint

Yes

22

No

$\frac{79}{101}$

Inadequate food involved in the complaint

Yes

20

No

$\frac{81}{101}$

Unsafe living conditions involved in the complaint

\begin{tabular}{lr} 
Yes & 15 \\
No & 86 \\
\hline 101
\end{tabular}

Emotional neglect involved in the complaint

Yes

12

No

$\frac{89}{101}$

Inadequate clothing involved in the complaint

Yes

No

$\frac{90}{101}$

Inadequate parenting involved in the complaint

Yes

No

$\frac{95}{101}$

Abandonment involved in the complaint

Yes

No

$\frac{94}{101}$ 
APPENDIX F

\section{KEY PUNCH CODING FORM}


Variable

Agency code

Agency case Number

Agency case number

Agency code

Source of complaint

Seriousness of situation

Discrediting information that legitimizes complaint

Evidence of complainant's discrediting of parents

Motivation for complaint

Appropriateness of complainant's suggested action to services provided by the agency

Complainant's recommended or implied action

The person with whom the child was living at the time of the complaint situation

How the complainant happened to see or know about the situation

Sex of complainant

Relationship between complainant and family

The length of time the situation had existed to the complainant's knowledge

Was the complainant caring for the child(ren) during the period of time of the complaint situation?

If yes, was it for pay?

Had the complainant ever taken care of the child(ren) in the past?

If yes, was it for pay?

Was a breakdown in, or a lack of a child care arrangement involved in the complaint situation in any way?

If yes, relationship of child care arrangement to the complaint situation

Person who was supposed to be providing child care
Variable

Code

Column

Cate-

Code

ID

ID

ID

AGCY

SR CE

SOS

DSCR

EVID

MOTV

1

2

gories

$\mathrm{ACT}$

10

RECM

11

8

LIVE

12

5

KNEW

13

14

4

SEX

REL

15

4

TIME

16

4

$\begin{array}{lll}\text { CARE } & 17 & 3\end{array}$

PAY

18

4

$\begin{array}{lll}\text { PAST } & 19 & 3\end{array}$

MONY $20 \quad 4$

ARNG 21

$\begin{array}{lll}\mathrm{RCCA} & 22 & 5\end{array}$

$\begin{array}{lll}\text { SUPD } & 23 & 5\end{array}$


Variable

The way the child care arrangement broke down

Did the complainant discuss the situation with anyone before making the complaint?

The agency's initial response to the complaint

Number of situations

Type of situation

Inadequate supervision

Abuse

Exposure to immoral environment

Inadequate medical care

Inadequate food

Unsafe, inadequate, or unsanitary housing

Emotional neglect

Inadequate clothing

Inadequate parenting

Abandonment

Reserved for control
Cate -

Variable

Code

Column

gories

DISC $\quad 25 \quad 2$

RSVP $26 \quad 5$

$\begin{array}{lll}\text { NSIT } & 27 & 7\end{array}$

$\begin{array}{lll}\text { TSIT } & 28 & 4\end{array}$

INSP $29 \quad 2$

ABUS $\quad 30 \quad 2$

IMOR . $31 \quad 2$

MED $\quad 32 \quad 2$

FOOD $\quad 33 \quad 2$

UNSF $\quad 34 \quad 2$

EMOT $\quad 35 \quad 2$

CLTH $36 \quad 2$

$\begin{array}{lll}\text { PRNT } & 37 & 2\end{array}$

$\begin{array}{lll}\text { ABAN } & 38 & 2\end{array}$

$39-40$ 


\section{APPENDIX G}

MATRIX OF CORRELATIONS AMONG VARIABLES STUDIED 


\begin{tabular}{|c|c|c|c|c|c|c|c|c|c|c|}
\hline TSIT & TSIT & SOS & ARNG & DISC & EVI D & MOTV & TI ME & PAST & CARE & AGCY \\
\hline sos & $.82 * * *$ & & & & & & & & & \\
\hline ARNG & $.79 * \%$ & $.54 \% * *$ & & & & & & & & \\
\hline DISC & $.47 \% *$ & -.28 & $-.44 * *$ & & & & & & & \\
\hline EVID & $\begin{array}{r}.39 * \\
-\quad 08^{\mathrm{a}} \\
\vdots .60^{\mathrm{b}} * \\
\end{array}$ & $\begin{array}{r}-.21 \\
.48 \mathrm{c} \\
.05 \mathrm{~d} \\
-.04 \mathrm{e} \\
\end{array}$ & $\begin{array}{l}.48^{* * *} \\
.83^{f * * * *} \\
.20^{8} \\
\end{array}$ & .14 & & & & & & \\
\hline MOTV & $.39 \% \div$ & $\begin{array}{l}-.52^{\mathrm{h}_{* * *}} \\
-.54^{\mathrm{i}}\end{array}$ & $-.27^{h}$ & & $\begin{array}{r}-.38^{j} \\
.03^{i}\end{array}$ & & & & & \\
\hline TIME & & $.16 *$ & & & $-.44 *$ & & & & & \\
\hline PAST & & -.04 & & & .09 & & & & & \\
\hline CARE & & -.03 & & & .39 & & & & & \\
\hline $\mathrm{AGCY}$ & $.20 \% *$ & .11 & $.14 * *$ & $-.79 * * *$ & .39 & $-.14 \% * *$ & $.30 \% * \%$ & .30 & -.33 & \\
\hline REL & .06 & .01 & $\begin{array}{l}-.05 \\
-.32^{h}\end{array}$ & $\begin{array}{r}-.28 \\
.19 . h\end{array}$ & .22 & $-.03^{h}$ & -.03 & $.97^{\mathrm{h}}$ & $.45^{\mathrm{h}}$ & .29 \\
\hline
\end{tabular}

${ }_{\text {for high SOS }}$
$b_{\text {for low SOS }}$
${ }_{\text {for inadequate supervision }}$
$d_{\text {for abuse }}$
$e_{\text {for neglect }}$
$f_{\text {for low SOS }}$
$g_{\text {for high SOS }}$
$h_{\text {for private sector }}$
${ }_{\text {for non-relatives }}$

$\mathrm{j}_{\text {for relatives }}$

All correlations are gammas or Yule's $Q$ for the total sample unless indicated.

$$
\begin{aligned}
& -\quad=p>.10 \\
& * \quad=p<.10 \\
& \cdots=p<.05 \\
& * *=p<.01
\end{aligned}
$$

REL 